Document downloaded from:

http://hdl.handle.net/10251/34801

This paper must be cited as:

García Prats, A.; Guillem Picó, S.; Martínez Alzamora, F.; Jiménez Bello, MA. (2012). Random scenarios generation with minimun energy consumption model for sectoring optimization in pressurized irrigation networks using a simulated annealing approach. Journal of Irrigation and Drainage Engineering. 138(7):613-624.

doi:10.1061/(ASCE)IR.1943-4774.0000452.

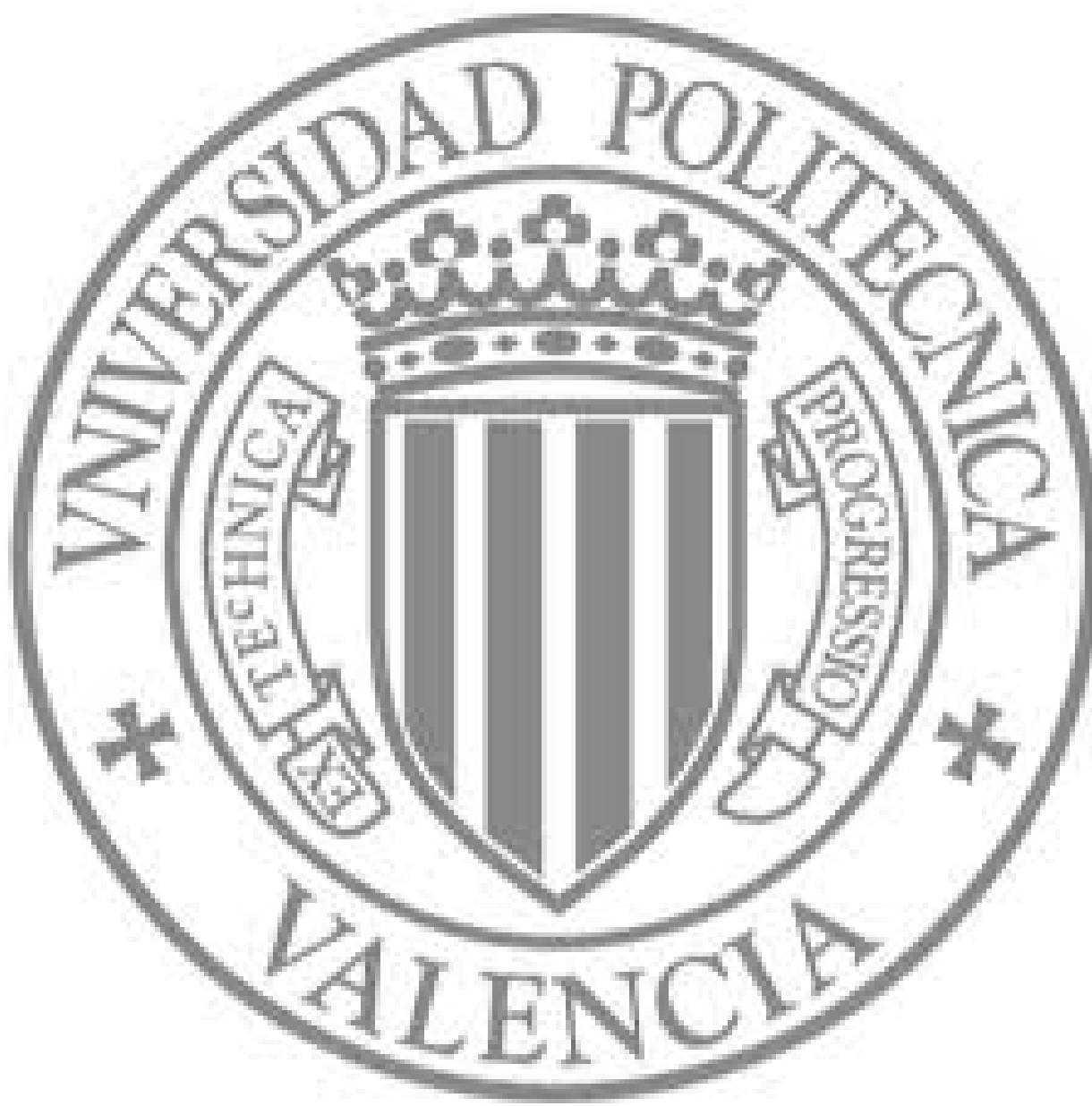

The final publication is available at

http://dx.doi.org/10.1061/(ASCE)IR.1943-4774.0000452

Copyright American Society of Civil Engineers 
6

\section{RANDOM SCENARIOS GENERATION WITH MINIMUM ENERGY CONSUMPTION MODEL FOR SECTORING OPTIMIZATION IN PRESSURIZED IRRIGATION NETWORKS USING A SIMULATED ANNEALING APPROACH} Alberto García Prats ${ }^{1}$; Santiago Guillem Picó2 ; Fernando Martínez Alzamora ${ }^{3}$; Miguel Ángel Jiménez Bello ${ }^{4}$.

\section{ABSTRACT}

A pressurized irrigation network may operate in two ways, namely, on demand and organized under operating sectors. In the first case, the user decides when to irrigate, and the pumping station has to meet the discharge and pressure head requirements of the group of users that is demanding water at any time. In the second case, the operating hydrants at a given moment are previously established, which permits identification of scenarios related to lesser energy consumption. In this work, a new model was developed that identifies such scenarios.

The optimization process is carried out by means of simulated annealing (SA). The model was applied to an example and the result obtained was compared with the same network operating on demand and sectorized using the criterion of hydrant elevation with respect to the pumping station. The scenario adopted for SA saved $11.8 \%$ and $15.5 \%$ in energy consumption compared with the two other scenarios, and decreased the installed power requirement by $38.3 \%$ and $21.6 \%$, respectively..

CE Database: Energy consumption; Irrigation systems; Pumping stations; Simulation; Monte Carlo method.

\footnotetext{
${ }^{1}$ Proffesor. Departamento de Ingeniería Hidráulica y Medio Ambiente, Universidad Politécnica de Valencia, Camino de Vera s/n 46022, (Valencia), España. E-mail: agprats@upvnet.upv.es.

2 Proffesor. Departamento de Ingeniería Cartográfica, Geodesia y Fotogrametría, Universidad Politécnica de Valencia, Camino de Vera s/n 46022, (Valencia), España.

3 Proffesor. Departamento de Ingeniería Hidráulica y Medio Ambiente, Universidad Politécnica de Valencia, Camino de Vera s/n 46022, (Valencia), España.

3 Proffesor. Departamento de Ingeniería Hidráulica y Medio Ambiente, Universidad Politécnica de Valencia, Camino de Vera s/n 46022, (Valencia), España.
} 
2 In the last few years, the modernization of irrigation facilities has consisted of replacement of

3 old open-channel-based transport, distribution, and water application systems by pressurized

4 irrigation networks. This has resulted in a more efficient use of water, but -at the same time- a

5 considerable increase in energy consumption (IDAE, 2008). Due to this, the Institute for

6 Diversification and Energy Savings of Spain (IDAE) proposes several measures to optimize

7 energy consumption, including network sectoring according to homogeneous energy demand

8 sectors and organization of farmers in irrigation turns. These operating sectors can be achieved

9 in a first approach by arranging the hydrants according to their elevation, measured from the

10 pumping station elevation. The number of operating sectors $N S$ should be compatible with the

11 daily average irrigation time required per hydrant $\left(t_{d}\right)$, so that all hydrants can be supplied within

12 the daily operation time (OT). Discharges per sector can be the same; in this case it will be

13 close to the value $Q_{\max } / N S, Q_{\max }$ being the maximum discharge when all hydrants are open

14 simultaneously.

This way of organizing irrigation turns or sectors allows for generation of the pressure head levels required in the pumping station in order to guarantee the minimum pressure head needed at the most unfavorable hydrant. If there are variable-speed pumps, the pumping station may be adapted to the different pressure head levels, and therefore a certain energy saving would be expected in comparison with an alternative organization in sectors including both low and great elevation hydrants (which would require high pressure heads). Nevertheless, this type of sector organization could become highly inefficient, since in certain cases head losses could be higher than the drop itself. Additionally, pump efficiency associated with the pump operating point could be low, which makes the problem of energy consumption more serious. Carrillo et al. (2010) proposed a hydrant grouping by means of cluster analysis, the studied variables being drop and distance to pumping system. Jimenez-Bello et al. (2010) developed a methodology to assign hydrants to operating sectors, thus minimizing the energy consumption based on genetic algorithms. 
1 On the other hand, many pressurized irrigation networks are planned to work on-demand. The

2 irrigation network delivers water with the flow rate and pressure required by farm irrigation

3 systems, and with time duration and frequency decided by the farmer. The number of hydrants

4 operating simultaneously is a stochastic process. Several methodologies have been developed in

5 order to determine the discharge of the network operating on-demand. Certainly, the most

6 popular method is the Clément's first formula (Clément, 1966). Each hydrant is assumed to

7 follow a binomial law, which tends to a normal distribution when the number of hydrants is

8 high.

9 In irrigation networks operating on-demand, the pumping station must be prepared to supply the maximum value of discharge corresponding to the bounding of all possible discharges for a determined operation quality (Moreno et al., 2007a; Lamaddalena and Sargadoy, 2000), and, at the same time, supply a sufficient pressure head at the pumping station to ensure the minimum required pressure head at the most unfavorable hydrant. However, a certain value of discharge $Q_{d i}$ can be obtained using multiple combinations of open hydrants, each one of them requiring a different pressure head $H_{i}$. Therefore, during the daily operation time, the network randomly draws a cloud of pairing values $Q_{d i}-H_{i}$ depending on the existing configuration of open hydrants.

17 Each open-hydrant configuration implies a pump operating point $Q_{d i}-H_{i}-\eta_{i}$ and is associated with an energy consumption of the pumping station. Moreno et al. (2007b) developed a model for analyzing energy efficiency at pumping stations and determined the sequence of pump activation. The same authors (Moreno et al., 2009) also proposed a decision support tool to obtain the theoretical characteristics and efficiency curves of the pumps, the number of pumps, and the number of frequency speed drives that minimize the total cost for a specific pumping station requirement. Planells et al. (2005) developed a support tool for dimensioning and regulating pumping stations. In all these cases, networks operate on-demand.

These previous studies appear to confirm that on-demand irrigation implies an important energy consumption, since the network must be designed in order to ensure a minimum required 
1 pressure at the most unfavorable hydrant, which means that when the water is supplied other

2 hydrants receive excessive pressure (Rodriguez et al., 2009). This is reduced by means of a flow

3 limiter and pressure reducing valves located in the hydrant.

4 Some authors propose an approach that combines the use of sectors and working on demand.

5 Rodriguez et al. (2009) obtains a certain energy saving in an on-demand network by dividing it

6 into two sectors depending on their drop from the pumping station. Both of them operate on-

7 demand during half the daily operation time.

8 Simulated Annealing is an easy-to-use and robust combinatorial heuristic optimization method.

9 Other authors have used this method to solve several problems. Reca et al. (2008) utilized SA to optimize the diameters of looped networks. Kuo et al. (2003) employed SA to plan an irrigation project. Tospornsampan et al. (2007) made use of SA to size the diameters of a water distribution network with split-pipes.

EPANET is a robust, well-known, and tested network solver model (Rossman 2000). It performs the simulation of hydraulic and water quality behavior within a pressurized pipe network in extended periods. It employs the gradient method for solving the mass and energy conservation equations. EPANET has a Programmer's Toolkit, which allows for incorporating the network solver engine into other models.

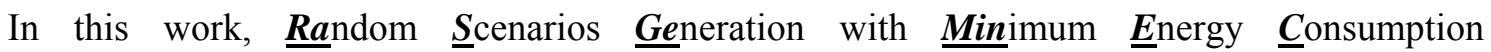
(RASGEMINEC) a model for the sectorization of pressurized irrigation networks was developed. The model is applicable for networks with flow-driven performance (Lamaddalena and Pereira, 2007a, 2007b; Calejo et al., 2008). Combinatorial heuristic optimization method of Simulated Annealing (SA) was used to find the best solution. Hydraulic requirements in the network of every scenario was analyzed by Epanet 2.0 engine. Energy demand was compared with on-demand performance and with sectoring based on an elevation criteria. 


\section{METHODOLOGY}

\section{Discharge calculation on-demand performance}

\section{Clément Methodology}

4 The calculation of the upstream discharge of a network, with a probability $P_{q}$ of not being 5 exceeded, may be performed using Clément's first formula (Clément, 1966).

6

$$
Q_{d}=\sum_{i=1}^{n} \mathrm{p}_{\mathrm{i}} \cdot d_{i}+\mathrm{U}\left(\mathrm{P}_{\mathrm{q}}\right) \cdot \sqrt{\sum_{i=1}^{n} \mathrm{p}_{\mathrm{i}} \cdot\left(1-p_{i}\right) \cdot d^{2}}
$$

8 where $Q_{d}=$ upstream discharge of a network $\left(\mathrm{L} \mathrm{s}^{-1}\right)$ that supplies $n$ hydrants with probability $P_{q}$ 9 of not being exceeded ( $P_{q}$ is called operation quality $-O Q$ - or supply guarantee); $p_{i}=$ probability that hydrant $i$ is open; $q_{i}=$ probability that hydrant $i$ is closed $\left(q_{i}=1-p_{i}\right) ; d_{i}=$ nominal discharge of hydrant $i\left(\mathrm{~L} \mathrm{~s}^{-1}\right)$; and $U\left(P_{q}\right)=$ value of standard normal variable for probability $P_{q}$.

The first Clément formula proposes a probabilistic solution based on two initial hypotheses: (a) The hydrant opening fits a binomial distribution and the hydrants operate randomly and independently. (b) All the hydrants of the network have the same opening probability for every

16 hour of the day and every day of the week of the peak period (Monserrat, 2004; Rodriguez et 17 al., 2007).

18 If the number of hydrants downstream is large enough, it can be assumed that the flow in a section fits a normal distribution.

$$
p_{i}=\frac{N_{s} \cdot t_{r}}{O T \cdot I R}=\frac{t_{d}}{O T}
$$


1 where $N_{s}=$ number of irrigation subunits per plot; $t_{r}=$ necessary irrigation set time to satisfy the

2 crop water requirement (h); $O T=$ network daily operation time $\left(\mathrm{h} \mathrm{d}^{-1}\right) ; I R=$ irrigation interval (d);

3 and $t_{d}=$ average daily irrigation time $\left(\mathrm{h} \mathrm{d}^{-1}\right)$.

4 Nominal discharge of hydrant $d_{i}$ can be calculated by (Planells, et al., 2001):

5

$$
d_{i}=2.778 \cdot A_{r s} \cdot \frac{S_{i}}{N_{s}}
$$

6 where 2.778 is a units adaptation coefficient $\left(\frac{10,000 \mathrm{~m}^{2} \cdot h a^{-1}}{3,600 s \cdot h^{-1}}\right) ; A_{r s}=$ average application rate of

7 the system $\left(\mathrm{L} \mathrm{m}^{-2} \mathrm{~h}^{-1}\right)$ in sprinkler irrigation or equivalent discharge per unit of area in 8 drip/microirrigation; $S_{i}=$ area of the plot (ha).

9 The average hydrant opening probability $p_{i}$ and nominal discharge hydrant, $d_{i}$ can be calculated 10 for each hydrant $i$ at a period of maximum water requirements.

11 The necessary irrigation set time to satisfy the crop water requirement is (Planells, et al. 2001):

$$
t_{r}=\frac{N T_{r} \cdot I R}{A_{r s}}
$$

where $N T_{r}=$ Crop gross irrigation requirements during the peak demand $\left(\mathrm{L} \mathrm{m}^{-2} \mathrm{~d}^{-1}\right)$.

\section{Monte Carlo simulation vs Clément's first formula}

Clément's methodology can be reduced to (Moreno, et al., 2007a):

$$
Q_{d}=\mu+U\left(P_{q}\right) \cdot \sigma
$$

Where $\mu=$ mean of normal density function; and $\sigma=$ standard deviation. random variable with a binomial behavior. The opening probability is known and equals $p_{i}$. 
1 When, in an iteration, $p_{i}=1$, the hydrant $i$ generates a discharge that equals the nominal

2 discharge $d_{i}$. When $p_{i}=0$, the hydrant $i$ is not working and its discharge is $d_{i}=0$. For each

3 iteration, the upstream discharge of the network $Q_{d i}$ is:

4

$$
Q_{d i}=\sum_{i=1}^{n} p_{i} \cdot d_{i}
$$

5 After a sufficiently large number of iterations (where the average $\mu$ does not change although

6 the number of iterations increases), we are able to calculate the average flow rate $\mu$, the standard

7 deviation $\sigma$, as well as the $Q_{d}$ value for all the percentiles can be calculated without the need of

8 applying Clément's first formula. The result of applying equation (5) with a determined

9 operation quality $(O Q)$ is equivalent to the $Q_{d}$ value corresponding to percentile $=O Q$, obtained

10 through the Monte Carlo simulation.

11 The advantage of applying a Monte Carlo simulation consists of being able to have multiple

12 scenarios of randomly generated configurations, and not a single design flow-rate (as provided

13 by Clément's first formula). Each one of these configurations can be later analysed by means of

14 Epanet 2.0 to obtain the $H_{i}$ value corresponding to every value of $Q_{d i}$.

\section{Discharge calculation on operating-sectors performance}

17 An operating sector is defined as a set of hydrants that operate simultaneously at a given time.

18 Nominal discharge of hydrant $i, d_{i}$ can be calculated by equation (3).

19 Discharge of every operation sector $Q_{s i}$ will be the sum of discharges of hydrants operating 20 simultaneously during a given time:

$$
Q_{s i}=\sum_{i=1}^{n} d_{i}
$$


1 The number of operating sectors $N S$ must be in accordance with the daily average irrigation

2 time required per hydrant $\left(t_{d}\right)$ in order to be able to supply all the hydrants within the daily

3 operation time $(O T)$

4

$6 \quad$ Pressure head requirements for each scenario: Hydraulic Simulation

7 Each scenario generated by a simultaneously-operating hydrant configuration, (both on-demand

8 performance and operating-sectors performance), requires a pressure head $H_{i}$ upstream of the

9 network, which guarantees the minimum pressure in the most unfavorable hydrant. This

10 pressure head upstream is obtained through a hydraulic simulation using the Epanet model

11 (Rossman, 2000). Therefore, the result yielded consists of pairing values, $Q_{s i}-H_{i}$ or $Q_{d i}-H_{i}$, as

12 appropriate.

13 It should be stated that the most unfavorable hydrant is selected among those operating at a

14 given moment for each configuration. Non-operating hydrants only require positive pressures.

\section{Pumping Station Requlation and Energy Consumption}

17 The characteristic and efficiency curves of commercial pumps $(Q-H$ and $Q-\eta)$, with fixed-speed and equal to nominal revolution number, can be approached by means of (Planells, et al., 2005):

19

$$
\left\{\begin{array}{l}
H=C+D \cdot Q^{2} \\
\eta=E \cdot Q+F \cdot Q^{2}
\end{array}\right.
$$

20 Where $C, D, E, F$ = pump coefficients obtained by regression analysis based on characteristics

21 curves of commercial pumps, $H=$ pressure head provided by one pump unit (m) when discharge

22 is $Q, Q=$ discharge produced by one unit pump when pressure head is $H(\mathrm{~L} / \mathrm{s}) . \quad \eta=$ pump

23 efficiency (\%). 
2 The equivalent equations for pumps working with variable-speed can, by using affinity laws, approached by (Planells, et al., 2005):

4

$$
\left\{\begin{array}{l}
H=\alpha^{2} \cdot C+D \cdot Q_{1}{ }^{2} \\
\eta=\frac{E}{\alpha} Q_{1}+\frac{F}{\alpha^{2}} Q_{1}{ }^{2}
\end{array}\right.
$$

6 Where $\alpha$, the relative revolution number for the pump $\left(\alpha=N_{p} / N_{0}\right) ; N_{0}=$ nominal revolution 7 number for the pump, $N_{p}=$ revolution number for the pump at a given time, $Q_{I}=$ discharge 8 produced by one unit variable-speed pump when pressure head is $H(\mathrm{~L} / \mathrm{s})$ and spin at $\alpha$ relative 9 revolution number.

10 Once we know the discharge and pressure head required by the network on a given open hydrants configuration, the power absorbed by a pumping station composed of $N_{v s}$ equal variable-speed pumps and $N_{f s}$ equal fixed-speed pumps arranged in parallel can be calculated as (Planells, et al., 2005):

$$
P_{a b s, i}=\frac{0.00981 \cdot Q_{v s} \cdot H}{\frac{E}{N_{v s} \cdot \alpha} \cdot Q_{v s}+\frac{F}{N_{v s}{ }^{2} \cdot \alpha^{2}} \cdot Q_{v s}{ }^{2}}+\frac{0.00981 \cdot Q_{f s} \cdot H}{\frac{E}{N_{f s} \cdot \alpha} \cdot Q_{v s}+\frac{F}{N_{f s}{ }^{2} \cdot \alpha^{2}} \cdot Q_{f s}{ }^{2}}
$$

15 Where, $P_{a b s, i}=$ power absorbed by pumping station $(\mathrm{kw})$ on a given scenario, $Q_{v s}=$ total discharge 16 of variable speed pumps $\left(\mathrm{L} \mathrm{s}^{-1}\right), Q_{f s}=$ total discharge of fixed-speed pumps $\left(\mathrm{L} \mathrm{s}^{-1}\right)$, being $\left(Q_{v s}+\right.$ $\left.17 Q_{f p}\right)=Q_{s i}$ or $Q_{d i}$ as appropriate.

18 Usually, pressure head at the pumping station is controlled by a pressure transducer and a programmable logic controller (PLC). Variable-speed pumps have shared regulation, i.e. spin at the same speed and always working. When demand exceeds the discharge capacity of variablespeed pumps, one unit of fixed-speed pump starts to work. At this moment, the discharge produced for every pump unit with fixed-speed $Q$ can be derived from equation (9) when pressure head upstream is $H_{i}$. The number of pump units needed is the integer $N_{f s}=Q_{s i} / Q$ or 
$1 Q_{d i} / Q$ as appropriate. Then, $Q_{f s}=Q \cdot N_{f s}$. Discharge produced for every variable-speed pump unit

2 can be obtained by $Q_{I}=\left(Q_{s i^{-}} Q_{f s}\right) / N_{v s}$ or $Q_{l}=\left(Q_{d i^{-}} Q_{f s}\right) / N_{v s}$ as appropriate. $N_{v s}$ must be a known

3 property of the pumping station.

4 Pump relative revolution number $\alpha$ can be derived from equation (10), when $Q_{l}$ is obtained.

5 Energy consumption is calculated as follows:

6 In operating-sectors performance:

7

$$
E=\sum_{i=1}^{N S} P_{a b s, i} \cdot t_{d}
$$

8 Where $E$ = energy consumption in one day of the month with maximum irrigation requirements 9 (July), in $\mathrm{kw} \cdot \mathrm{h} \cdot \mathrm{d}^{-1}$.

In on-demand performance, we have to calculate the partial time along which the network is operating within each pair $Q_{d i} H_{i}$, based on the relative frequencies obtained in the Monte Carlo analysis (Moreno et al., 2009). For this purpose, the discharge range (0 to $Q_{d i, \max }$ ) is divided into 10 intervals, and each one of them into 10 pressure head intervals $\left(H_{i, \min }\right.$ to $\left.H_{i, \max }\right)$. The calculation of the relative frequencies at which the network operates in each interval of flowrate and pressure allows us to extrapolate the percentage of the $O T$ that the network works with a certain operating point $Q_{d i}-H_{i}-\eta_{i}$, therefore its energy consumption (for one day in the month with maximum irrigation requirements, in this case July, in $\left.\mathrm{kw} \cdot \mathrm{h} \mathrm{d}^{-1}\right)$.

\section{Operating Sectors Optimization}

\section{Simulated Annealing Algorithm.}

21 The complete investigation of all possible configurations leads to a large number of cases

22 (Lamaddalena and Sagardoy, 2000). Since it is not feasible to investigate all possible configurations, we needed an algorithm to assign hydrants to operating sectors. For this reason 
1

2

3

4 Carlo methods in statistical mechanics (Tospornsampan, et al., 2007). Kirkpatrick et al. (1983)

5

we used the heuristic algorithm of combinatorial optimization named Simulated Annealing (SA).

SA receives its name due to its analogy to physical annealing in solids, inspired from Monte took the idea of annealing from Metropolis (1953) algorithm and applied it to combinatorial optimization problems. The SA algorithm starts by randomly generating the initial configuration, which is analogous to the current solution that is composed of a set of decision variables of the problem, within a feasible region at a high initial temperature value $\left(T_{0}\right)$. Then, the new configuration is generated from the corresponding neighborhood of the current solution using a generation mechanism that implements a random rearrangement or perturbation of variables of the current configuration (Tospornsampan, et al., 2007). One rearrangement is referred to as a transition. Acceptance of a transition from one state to another is dependent on the Metropolis criterion given by $P(\Delta E)=\min \left[1, \exp \left(-\Delta E / T_{t}\right)\right]$ where $P(\Delta E)$ is probability of acceptance, $\Delta E=f\left(S_{j}\right)-f\left(S_{i}\right)$ is the difference between the objective function values of the new current configuration $S_{j}$ and the current configuration $S_{i}$, and $T_{t}$ is the current temperature, used to control the acceptance of modifications. If the new configuration is found to have a better fitness (evaluated by the objective function of the system) than its predecessor, then it is retained and the current configuration is discarded. If the new configuration is found to have a worse fitness than its predecessor, it may be retained if the Boltzmann probability, $P_{r}=\exp (-$ $\left.\Delta E / T_{t}\right)$, is greater than the generated uniform random number $r$ distributed in the interval $(0,1)$. At the same temperature, the rearrangement must proceed long enough for sufficient number of transitions that allow the system to reach a steady state. The aim of the application of this criterion of acceptance is to avoid being caught into local minimums.

Then the temperature is slowly decreased based on annealing schedule and the process is repeated successively until the stopping criterion is satisfied. The general procedure of SA applied in this study is (Tospornsampan, et al., 2007): 
1

2

3

4

5

6

7

8

9

10

- Generate an initial configuration $S_{i}$

- Select an initial temperature $T_{0}$

- Set temperature change counter, $t=1$

- $T_{t}=T_{0}$

- Repeat Until $T_{t}=T_{f}$ or stopping criterion is met

o Set repetition counter (number of transitions), $L=0$

o Repeat Until $L=L_{t}$

- Rearrangement by generating configuration $S_{j}$, a neighbor of $S_{i}$

- Calculate $\Delta E=f\left(S_{j}\right)-f\left(S_{i}\right)$, the improvement of objective function

o If $\Delta \mathrm{E}<0$ then $S_{i}=S_{j}$

o Else if random $(0,1)<\exp (-\Delta E / T)$ then $S_{i}=S_{j}$

0 $\quad L=L+1$

o End Repeat

- $t=t+1$

- $T_{t}=\alpha_{c} \cdot T_{t-1}$

- End Repeat

\section{Annealing Scheduling}

Annealing scheduling is the heart of SA. Avoidance of getting trapped in local minima is dependent on the annealing schedule that includes a) the choice of an initial temperature, b) the number of transitions at each temperature $L_{t}$, and c) the decrease rate of the temperature at each step as cooling proceeds (or cooling rate $\alpha_{c}$ ). (Tospornsampan, et al., 2007).

A temperature parameter is used to control the acceptance of modifications (rearrangements).

24 The initial temperature value, $T_{0}$, must be high enough to ensure a large number of acceptances 25 at the initial stages. It is gradually decreased over time depending on $\alpha_{c}$ which is the coefficient 
1

2

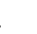

used to decrease the temperature at the end of every temperature change counter. The cooling schedule is described as follows (Tospornsampan, et al., 2007):

$$
T_{t}=\alpha_{c} \cdot T_{t-1}
$$

where $T_{t}$ and $T_{t-1}$ are the temperatures at the end and beginning of the cooling schedule at temperature change counter $t$ and $\alpha_{c}$ is the cooling rate which can range from 0 to 1 . The value of $\alpha_{c}$ is accomplished in the range between 0.5 and 0.90 .

The stopping criterion is used to terminate the annealing process. In this study, the annealing process may be over when the final temperature reaches a prefixed specific level $T_{t}=T_{f}=1$.

At each temperature, the configuration of the system is changed using a generation mechanism that implements a random perturbation of variables of current state. The total number of transitions at a given temperature $T$ constitutes a homogenous Markov chain of length given by the parameter $L_{t}$. Setting parameters for SA is a specific problem and is best accomplished through trial and error.

In our case, we will apply the algorithm with different values for the parameters: $T_{0}(10 ; 100$ and 1,000); $L_{t}\left(10,100 ; 1,000 ; 10,000\right.$ and 100,000); and $\alpha_{c}(0.5 ; 0.6 ; 0.7 ; 0.8$ and 0.9).

\section{Rearrangement of the system}

Rearrangement or neighborhood generation is carried out by randomly changing the current configuration into a new one. In each step of the algorithm, a change of configuration is produced, and then its cost is evaluated. The objective function $E$, evaluated in each iteration, is the power consumption $\left(\mathrm{kw} \cdot \mathrm{h} \mathrm{d} \mathrm{d}^{-1}\right)$ of a working day at the time of maximum hydric requirements (July) (Equation 12). 
1 The starting scenario is a network organized according to the elevation criteria sectoring.

2 Hydrants are put in increasing order of elevation, and their discharges are accumulated forming

$3 \quad N S$ sectors that have similar $Q_{s}$ among one another.

4 The new configuration is chosen at random in the neighborhood of the current configuration. In

5 the algorithm implementation proposed, this neighborhood includes the configuration having all

6 the hydrants operating in the same current operating sector, but one. One hydrant (from 1 to $n$ )

7 and one operating sector (from 1 to $N S$ ) are randomly selected. The selected hydrant stops

8 working in the current sector and begins to operate in a new one. The new configuration is

9 analyzed by the Epanet model and energy consumption is calculated. If that configuration is not

10 feasible from a hydraulic point of view, it is directly rejected and another configuration is

11 searched for. The new configuration (hydraulically feasible) is accepted or not, according to the

12 Metropolis criterion. If it is accepted, this configuration will be used as the starting point for the next step. If not, the original configuration will play this role.

14 One configuration is hydraulically feasible when all pipes have a speed under $3 \mathrm{~m} \mathrm{~s}^{-1}$, the pressure head is $>0$ in non-operating hydrants and other nodes of the network, and $>25 \mathrm{~m}$ in operating hydrants.

\section{$\underline{\text { Study area }}$}

The area chosen for applying the decision support tool developed corresponds to traditional irrigated farming lands in the east of Spain, namely in the Valencian Community, where water is distributed by means of a flow-driven performance pressure distribution network and with drip irrigation in plots since 1998, which replaced the channel irrigation system and surface irrigation previously used. The total surface area supplied is 191.15 ha and citrus trees are cropped. The total number of hydrants (individual plots) is $n=385$, grouped in 47 control units. The pumping station is composed of 3 equal pumps of $63 \mathrm{~kW}$ each and $N_{0}=2900 \mathrm{rpm}$. One of them is equipped with variable speed drives and the others are fixed-speed pumps. Pump 
1

2

3

4 The billing structure of the electric company tariff has two periods: One period of $16 \mathrm{~h} \mathrm{~d}^{-1}$ with

5 ordinary rate and $8 \mathrm{~h} \mathrm{~d}^{-1}$ with peak rate. Consequently, daily $O T$ is usually fixed around $16 \mathrm{~h} \mathrm{~d}^{-1}$.

6 Crop gross irrigation requirements during the peak demand (average value for July) is $3,95 \mathrm{~L} \mathrm{~m}^{-}$

$7 \quad{ }^{2} \mathrm{~d}^{-1}$. Due to the high degree of parceling, only one subunit $N_{s}$ exists in every plot. In drip

8 irrigation, watering usually takes place daily in the month of peak demand, therefore irrigation

9 interval (IR) will be 1.

$10 A_{r s}$ were defined as average application rate of the system $\left(\mathrm{L} \mathrm{m}^{-2} \mathrm{~h}^{-1}\right)$ in sprinkler irrigation or 11 equivalent discharge per unit of area in drip/microirrigation. Citrus trees have a typical crop 12 pattern with 375 plants per hectare and 8 emitters of drip irrigation with a $4 \mathrm{~L} \mathrm{~h}^{-1}$ of discharge.

13 Therefore $A_{r s}$ :

17 The number of operating sectors $(N S)$ will be 5 because $3.29 \mathrm{~h} \mathrm{x} 5=16.45 \mathrm{~h} \mathrm{~d}^{-1}$, close to $16 \mathrm{~h} \mathrm{~d}^{-}$

18 . The operation time $(O T)$ in on-demand performance will be $16.45 \mathrm{~h}$ too, in order to compare 19 results.

Finally, applying equation 4 we obtain the last irrigation related parameter $p_{i}$ :

$$
p_{i}=\frac{N_{s} \cdot t_{r}}{O T \cdot I R}=\frac{1 \cdot 3.29}{16,45 \cdot 1}=0.2
$$


2 In a first approach, we arranged the hydrants according to their elevation, measured from the pumping station elevation. Hydrant discharges were accumulated, forming 5 operating sectors

4 with similar $Q_{s}$. By applying equations (9) to (12), we calculated the number of pumps required 5 in each sector, as well as the operating point for each pump, and the energy consumed. Table 1

6 shows the results obtained for the starting situation.

7 The aforementioned scenario was utilized as a starting point in the optimization by means of 8 SA. By applying the annealing scheduling, a great deal of annealing runs were performed for 9 different values of the parameters $T_{0}\left(10 ; 100\right.$ and 1,000); $L_{t}(10,100 ; 1,000 ; 10,000$ and 100,000); and $\alpha_{c}(0.5 ; 0.6 ; 0.7 ; 0.8$ and 0.9$)$.

Each combination of parameters is associated to a total number of iterations (one hydraulically feasible scenario is studied in each iteration); they were tested and their energy consumption was calculated. The higher the values of $T_{0,} L_{t}$, and $\alpha_{c}$, the more iterations, and therefore the higher computational effort is required. Once the algorithm had been run for all the aforementioned parameter combinations, the evolution of the optimum solution found for SA with varying parameters was studied. Table 2 summarizes the solutions obtained depending on the parameters employed.

The effect of $T_{o}$ value on the solution found is shown in Fig. 1, 2, and 3. Low values of $T_{o}$ (Figure 1) gave rise to unstable situations when $L_{t}$ y $\alpha_{c}$ were increased. In this case, the number of iterations were increased, but the solution found may improve or worsen compared to the previous one, following no model at all. This is due to the fact that the total number of explored scenarios is still very low. Nevertheless, with medium and high $T_{o}$ values (Figures 2 and 3), the solution became more stable with increasing values of $L_{t} \mathrm{y} \alpha_{c .}$ and we achieved significant improvements with respect to the initial situation. combination. The same effect is observed when the total number of explored scenarios is plotted 
against the solution found (energy consumption) for each $T_{o}$. Figures 4 shows that - for $T_{o}=10$ the solutions are unstable, being able to improve or get worse with each value of $L_{t}$ and $\alpha_{c}$. However, with medium and high values of $T_{o}$, an increase in the number of explored scenarios enhances the solutions obtained.

Although the best solution was found for $T_{0}=100, L_{t}=100,000$ and $\alpha_{c}=0.6$ with an energy consumption of $2049 \mathrm{kw} \cdot \mathrm{h} \mathrm{d}{ }^{-1}$, any solution with $T_{0} \geq 100$ and $L_{t} \geq 10,000$ could be acceptable, which is equivalent to explore at least 100,000 scenarios. The energy saving vs. the initial solution is $375 \mathrm{kw} \cdot \mathrm{h} \mathrm{d}^{-1}(15.5 \%)$.

The operating point of the pumping station in every sector for the best solution found with SA is summarized in Table 3.

Finally we simulated the functioning of the network working on-demand. For this purpose, a Monte Carlo simulation was run as described under Methodology. The number of iterations or explored scenarios was 100,000 . Each one of them described a scenario of operating hydrants with an opening probability $p_{i}=0.2$ following a binomial probability law. The scenarios were analysed in the Epanet hydraulic model. Figure 5 shows the pairing values cloud $Q_{d i}-H_{i}$ obtained.

The discharge range was divided into 10 intervals, and each one of them into 10 pressure head intervals. The operating time of the network in each interval was obtained by means of a relative frequency analysis. Both the operating point of the pumps and the energy consumption of the network in each interval are got by applying equations (9), (10), (11), and (12). Total energy consumption along an irrigation day was $2,321 \mathrm{kw} \cdot \mathrm{h} \cdot \mathrm{d}^{-1}$. Table 4 shows in detail the energy consumption calculation.

In an on-demand operating network project design, the operation quality (OQ) should be defined with the purpose of calculating the operating point at design level. Only in case of $O Q=100$, any pair of values $Q_{d i}-H_{i}$ will be correctly supplied. Usually values between 96 and 99 are used. Thus, there will be pairing values $Q_{d i}-H_{i}$ that will remain outside the pump reach, and 
1

2

pressures generated in the network will be lower than required. Table 5 shows the number of pumps required and their time of operation per day to ensure that operating on-demand scenario fulfils an operation quality of 100 . Since there are only 3 pumps, the network cannot guarantee the minimum pressure requirements for $0.35 \mathrm{~h} \mathrm{~d}^{-1}(2.2 \%$ of $O T)$.

The instantaneous power required is $P_{a b s}=235.6 \mathrm{kw}$, provided that we only refer to the scenarios that can be covered with the existing pumping station. If more pump groups were installed, all cases could be dealt with $(O Q=100)$, but the instantaneous power required would be $P_{a b s}=279,3$ kw.

A comparison of energy consumption among the three cases analyzed showed that the ondemand operating case had a lower energy consumption $\left(2,321 \mathrm{kw} \cdot \mathrm{h} \cdot \mathrm{d}^{-1}\right)$ than the operating sectors case when the hydrants were arranged according to their elevation. $\left(2,423 \mathrm{kw} \cdot \mathrm{h} \cdot \mathrm{d}^{-1}\right)$, but a higher energy consumption than the operating sector case optimized by SA $\left(2,049 \mathrm{kw} \cdot \mathrm{h} \cdot \mathrm{d}^{-1}\right)$. The network optimized using SA allowed for a daily saving of 375 and $273 \mathrm{kw} \cdot \mathrm{h}$ respectively (equal to $15.5 \%$ and $11.7 \%$ ) per working day in the month of maximum irrigation requirement.

Electric tariffs usually have a dual structure, energy consumed and total power contracted being independent terms. Every month a fixed amount per $\mathrm{kw}$ of contracted power is paid, regardless of the energy consumption. If the installation requires an instant power higher than that contracted, important penalties are applied. In the described case study, the network operating on-demand had the highest instantaneous power requirement (236 kw), followed by the network sectorized by hydrant elevation (185 kw), and finally the network optimized with SA (145 kw). Thus, the network sectorized with SA needed $38.3 \%$ and $21.6 \%$ less instantaneous power, respectively.

Results can be compared with other works that aim at looking for energy savings through the hydraulically management of the network. Talking about saving is very important to define what initial situation we are comparing to. Carrillo et al. (2010) proposed a hydrant grouping in two sectors; both of them operating on-demand during half the daily operation time. They 


\section{CONCLUSIONS}

24 The random generation of scenarios connected to a hydraulic model such as Epanet is a

compared an on-demand operating network with other way to organize the same on-demand operating network. Savings achieved were $8 \%$ and $5 \%$ in two application cases. Jimenez-Bello et al. (2010) developed a similar approach to ours, but using genetic algorithms to optimize the energy consumption. They compared the optimized sectorization with the operating sectors programmed by the users without following any criteria or guidelines in a case application for the year 2006. They saved $34.6 \%$ through the optimized sectorization. The worst one is the initial scenario, whereas the best one is the solution achieved. Any previous work compared an on-demand operating network versus an optimized sectoring operating network.

Finally, two practical considerations concerning the implementation in a real case:

(1). In order to implement the optimized operating sectors, two alternatives are possible. Firstly, if a collective irrigation control system exists, all hydrants belonging to the same operating sectors should be programmed to open at the same time. If an irrigation control system does not exist, and the users are responsible to open and close their hydrant, a schedule must be supplied to each user with the opening and closing time.

(2). In drip irrigation systems design, the irrigation time $t_{r}$ is usually defined for the day of the month with maximum irrigation requirements, in which daily irrigation is needed $(I R=1)$. In order to avoid the modification of the wetted bulb, the irrigation time remains constant over the season, but the irrigation frequency (IR) is reduced as the irrigation requirements decreases. (watering once every two days, three days, and so on). Thus, energy consumption is the same for every irrigation day, regardless of the month, and optimization performed for one watering day of July is valid for other watering day of the year. 
1 systematic generation of all possible scenarios, some sort of algorithm is required to lead us to

2 the best solution. Simulated Annealing (SA) perfectly meets this requirement, and it is a new,

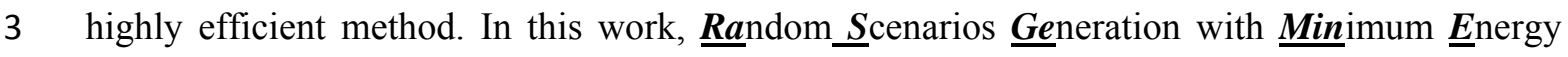

4 Consumption (RASGEMINEC) model for sectoring pressurized irrigation networks was

5 developed.

6 The work carried out so far lead us to the following conclusions:

7 The organization of operating sectors with similar discharge by arranging the hydrants

8 according to their elevation, measured from the pumping station elevation is not a suitable

9 method. The result will depend on the topology of the network, but it may occur (as in this case)

10 that the energy consumption be even higher than that of the network if operating on-demand.

11 For the case study presented, the use of SA achieved an $11.7 \%$ energy saving when compared

12 to the same network operating on-demand, and $15.5 \%$ when it is sectorized according to the

13 hydrant elevation criteria. At the same time, it required $38.3 \%$ and $21.6 \%$ less power

14 respectively. As we explained above, the energy saving corresponded to one day of irrigation in

15 the month of maximum water requirements (July), but may also represent the saving obtained on irrigation days during the rest of the season. It is therefore equivalent to the annual savings.

17 As regards the algorithm parameters defined in the annealing scheduling, it can be inferred that the initial temperature $T_{o}$ should equal (or be higher than) 100, whereas chain length $L_{t}$ should equal (or be higher than) 1000. This leads us to explore at least 100,000 hydraulic feasible scenarios.

21 When the network operates on-demand, $2.2 \%$ of the time is spent with discharge and pressure head requirements that cannot be obtained by the pumping station. We can say that the network operates in a fault situation. Contrary to this, the network sectorized and optimized with SA operates with an absolute reliability, since it does not accept unattended scenarios. 
1 If we design the on-demand network with $O Q=100$ to deal with all possible cases, the pumping

2 station has to be equipped with excess of capacity. As mentioned above, electric tariffs usually

3 have a dual structure, energy consumed and total power contracted being independent terms.

4 Therefore, with or without the excess of capacity in the pumping stations, the final energy $5 \quad$ invoice would be heavily penalized.

6

7 
2 Calejo, M.J., Lamaddalena, N., Teixeira, J.L., and Pereira, L.S. (2008). Performance 3 analysis of pressurized irrigation systems operating on-demand using flow-driven 4 simulation models. Agric. Water Management, 95, 154-162.

5

6 Carrillo, M.T., Rodriguez, J.A., Montesinos, P., Lopez, R., and Camacho, E. (2010).

7 Low energy consumption seasonal calendar for sectoring operation in presurized 8 irrigation networks. Irrigation Science, Published on line.

9

10 Clément, R. (1966). Calcul des debits dans les reseaux d'irrigation fonctionant a la demande. Houille Blanche, 5, 553-575.

IDAE (2008). Protocolo de auditoría energética en Comunidades de Regantes. Ministerio de Industria, Turismo y Comercio, Spain. 68 pp.

Jimenez-Bello, M.A., Martinez Alzamora, F., Bou Soler, V., and Bartoli Ayala, H.J. (2010). Methodology for grouping intakes of pressurised irrigation networks into sectors to minimize energy consumption. Biosystems Engineering, 105, 429-438.

20 Kirkpatrick, S., Gelatt, C.D., and Vecchi, M.P. (1983). Optimization by Simulated Annealing. Science, vol. 220, no. 4598, pp. 671-680.

23 Kuo, S.-F., Liu, C.-W., and Chen, S.-K. (2003). "Comparative study of optimization 24 techniques for irrigation project planning." Journal of American Water Resources 25 Association, 39 (1), 59-73. 
2 Lamaddalena, N., and Pereira, L.S., (2007a). Assessing the impact of flow regulators

3 with a pressure-driven performance analysis model. Agricultural Water Management, $490(1), 28-35$.

5

6 Lamaddalena, N., and Pereira, L.S., (2007b). Pressure-driven modeling for performance 7 analysis of irrigation systems operating on demand. Agricultural Water Management, $890(1), 36-44$.

9

10 Lamaddalena, N., and Sagardoy, J.A. (2000). Performance Analysis of On-demand 11 Pressurized Irrigation Systems. Paper 59. FAO. Irrigation and Drainage, Rome, Italy.

13 Metropolis, N., Rosenbluth, A., Rosenbluth, M., Teller, A., and Teller, E. (1953).

14 Equations of state calculations by fast computing machines. J. Chemical Phys., 21, $15 \quad 1087-1092$.

17 Monserrat, J., Poch, R., Colomer, M.A., and Mora, F. (2004). Analysis of Clément's 18 first formula for irrigation distribution networks. Journal of Irrigation and Drainage 19 Engineering, 130-2, 99-105.

20

21 Moreno, M.A., Planells, P., Ortega, J.F., and Tarjuelo, J.M. (2007a). New methodology 22 to evaluate flow rates in on-demand irrigation networks. Journal of Irrigation and 23 Drainage Engineering, 133(4), 298-306. 
1 Moreno, M.A., Carrion, P., Planells, P., Ortega, J.F., and Tarjuelo, J.M. (2007b).

2 Measurement and improvement of the energy efficiency at pumping stations.

3 Biosystems Engineering, 98, 479-486.

4

5 Moreno, M.A., Planells, P., Córcoles, J.I., Tarjuelo, J.M., and Carrion, P. (2009).

6 Development of a new methodology to obtain the characteristic pump curves that

7 minimize the total cost at pumping stations. Biosystems Engineering, 102, 95-105.

8

9 Planells, P., Tarjuelo, J.M., Ortega, J.F., and Casanova, M.I. (2001). Design of water 10 distribution networks for on-demand irrigation. Irrigation Science, 20, 189-201.

Planells, P., Carrion, P.A., Ortega, J.F., Moreno, M.A., and Tarjuelo, J.M. (2005).

Pumping selection and regulation for water distribution networks. Journal of Irrigation and Drainage Engineering, 131(3), 273-281.

Reca, J., Martinez, J., Gil, C., and Baños, R. (2008). "Application of several metaheuristic techniques to the optimization of real looped water distribution networks". Water Resour. Manag. 22. 1367-1379.

Rodriguez Díaz, J.A., Camacho Poyato, E., and López Luque, R. (2007). Model to 21 forecast maximum flows in on-demand irrigation distribution networks. Journal of 22 Irrigation and Drainage Engineering, 133(3), 222-231. 
1 Rodriguez Diaz, J.A., López Luque, R., Carrillo Cobo, M.T., Montesinos, P., ad

2 Camacho Poyato, E. (2009). Exploring energy saving scenarios for on-demand 3 pressurized irrigation networks. Biosystems Engineering, 104, 552-561.

4

5 Rossman, L.A., (2000). EPANET User Manual. US Environmental Protection Agency,

6 Drinking Water Research Division, Risk Reduction Engineering Laboratory, 7 Cincinnaty, Ohio, USA. 200 pp.

8

9 Tospornsampan, J., Kita, I., Ishii, M., and Kitamura, Y. (2007). Split-Pipe Design of 10 Water Distribution Network Using Simulated Annealing. International Journal of 11 Computer and Information Engineering, 1:3, 154-164. 


\section{$1 \quad$ Notation}

$2 \alpha=$ pump relative revolution number

$3 \quad \alpha_{c}=$ cooling rate

$4 \sigma$-standard deviation of normal density function

$5 \quad \eta=$ pump efficiency $(\%)$

$6 \quad \eta_{i}=$ pump efficiency for each iteration or scenario explored (\%)

$7 \mu=$ mean of normal density function

$8 A_{r s}=$ average application rate of the system in sprinkler irrigation or equivalent discharge per unit 9 of area in drip/microirrigation. $\left(\mathrm{L} \mathrm{m}^{-2} \mathrm{~h}^{-1}\right)$

$10 C, D, E, F=$ pump coefficients obtained by regression analysis based on characteristics curves 11 of commercial pumps

$13 d_{i}=$ nominal discharge of hydrant $i\left(\mathrm{~L} \mathrm{~s}^{-1}\right)$

$14 E=$ energy consumption in one day of the month with maximum irrigation requirements -July$15\left(\mathrm{kw} \cdot \mathrm{h} \mathrm{d}^{-1}\right)$

$16 \Delta E=$ difference between the objective function values of the new current configuration $S_{j}$ and

17 the current configuration $S_{i}$

$18 H_{i}=$ upstream pressure head that guarantee the minimum pressure head needed at the most 19 unfavorable hydrant, for each iteration or scenario explored (m)

$20 H_{i, m i n}=$ minimum value of $H_{i}$ found in all iterations or scenarios explored (m)

$21 \quad H_{i, \max }=$ maximum value of $H_{i}$ found in all iterations or scenarios explored (m)

$22 H=$ pressure head provided by one pump unit when discharge is $Q(\mathrm{~m})$

$23 I R=$ irrigation interval (d) 
$1 \quad L_{t}=$ number of transitions at each temperature

$2 \quad N_{0}=$ pump nominal revolution number (rpm)

$3 \quad N_{f s}=$ number of equal fixed-speed pumps arranged in parallel

$4 \quad N_{p}=$ pump revolution number at a given time (rpm)

$5 N_{s}=$ number of irrigation subunits per plot

$6 \quad N S=$ number of operating sectors

$7 \quad N_{v s}=$ number of equal variable-speed pumps arranged in parallel

$8 N T_{r}=$ Crop gross irrigation requirements during the peak demand $\left(\mathrm{L} \mathrm{m}^{-2} \mathrm{~d}^{-1}\right)$

$9 O Q=$ operation quality or supply guarantee

$10 O T=$ network daily operation time $\left(\mathrm{h} \mathrm{d}^{-1}\right)$

$11 P_{a b s, i}=$ power absorbed by pumping station on a given scenario (kw)

$12 \quad p_{i}=$ probability that hydrant $i$ is open

$13 P(\Delta E)=$ probability of acceptance of a transition from one state to another

$14 \quad P_{r}=$ Boltzmann probability

$15 q_{i}=$ probability that hydrant $i$ is closed $\left(q_{i}=1-p_{i}\right)$

$16 Q=$ discharge produced by one unit pump when pressure head is $H\left(\mathrm{~L} \mathrm{~s}^{-1}\right)$

$17 Q_{f s}=$ total discharge of fixed-speed pumps $\left(\mathrm{L} \mathrm{s}^{-1}\right)$

$18 Q_{d}=$ upstream discharge of a network $\left(\mathrm{L} \mathrm{s}^{-1}\right)$ that supplies $n$ hydrants with probability $P_{q}$ of not

19 being exceeded

20

$Q_{d i}-H_{i^{-}} \eta_{I}=$ pump operating point 
$1 Q_{d i}=$ upstream discharge of the network, for each iteration or scenario explored operating on-

2 demand $\left(\mathrm{L} \mathrm{s}^{-1}\right)$

$3 Q_{d i, \max }=$ maximum value of $Q_{d i}$ found in all iterations or scenarios explored operating on-

4 demand $\left(\mathrm{L} \mathrm{s}^{-1}\right)$

$5 \quad Q_{s i}=$ upstream discharge of the network, for each iteration or scenario explored under operating

6 sectors $\left(\mathrm{L} \mathrm{s}^{-1}\right)$

$7 \quad Q_{v s}=$ total discharge of variable speed pumps $\left(\mathrm{L} \mathrm{s}^{-1}\right)$

$8 Q_{I}=$ discharge produced by one unit variable-speed pump when pressure head is $H(\mathrm{~L} / \mathrm{s})$

$9 \quad S_{i}=$ area of the plot (ha)

$10 t_{d}=$ average daily irrigation time $\left(\mathrm{h} \mathrm{d}^{-1}\right)$

$11 t_{r}=$ necessary irrigation set time to satisfy the crop water requirement

$12 T_{f}=$ final temperature that ends the cooling schedule

$13 T_{0=}$ initial temperature value

$14 T_{t}=$ current temperature at the end of the cooling schedule

$15 T_{t-1}=$ temperature at the beginning of the cooling schedule

$16 U\left(P_{q}\right)=$ value of standard normal variable for probability $O Q$ 


\section{$1 \quad$ Figures}

2

3 Figure 1. Effect of Cooling Factor and Chain Length for $\mathrm{T}_{0}=10$.

4 Figure 2. Effect of Cooling Factor and Chain Length for $\mathrm{T}_{0}=100$.

5 Figure 3. Effect of Cooling Factor and Chain Length for $\mathrm{T}_{0}=100$.

6 Figure 4. Energy consumptions vs. number of scenarios explored and $\mathrm{T}_{\mathrm{o}}$.

7 Figure 5. Cloud of $\mathrm{Q}_{\mathrm{di}}-\mathrm{H}_{\mathrm{i}}$ pairing values generated by the Monte Carlo simulation (operating on8 demand). 


\section{$1 \quad$ Tables}

2 Table 1. Energy consumption in the sectorized network according to the elevation of hydrants.

3 Table 2. Simulated annealing solutions achieved.

$4 \quad$ Table 3. Energy consumption in the network under the scenario selected by SA.

5 Table 4. Detailed Energy consumption calculation on-demand functioning.

6 Table 5. Percentage of operating time related with the number of pumps needed. 


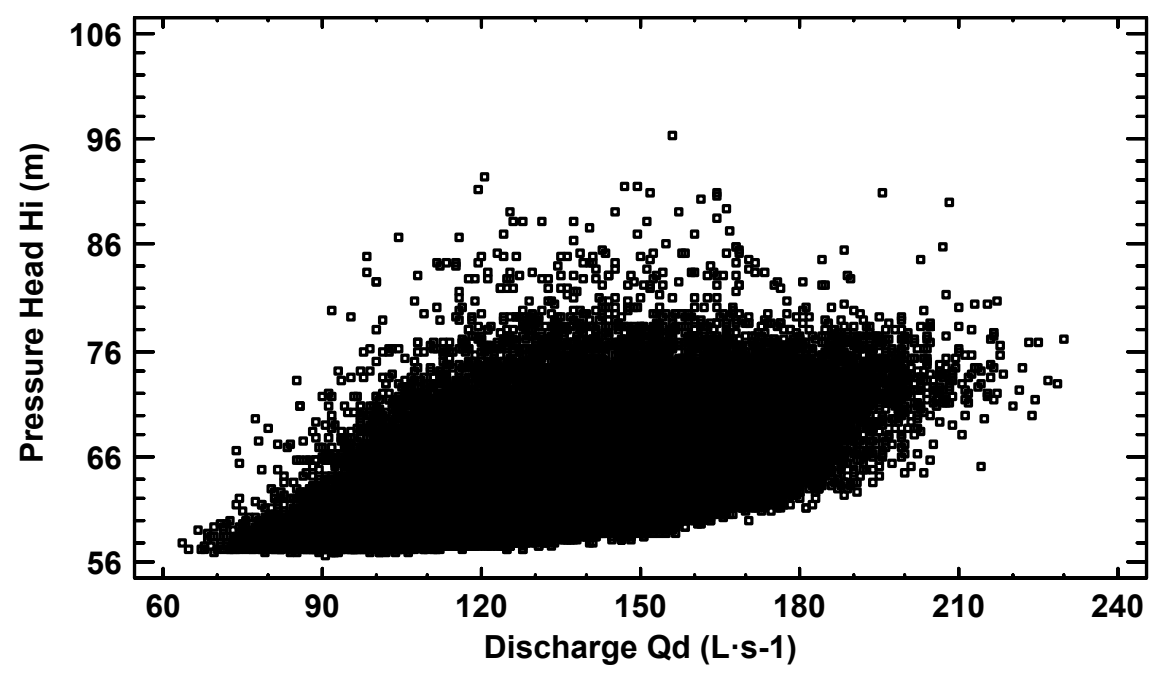




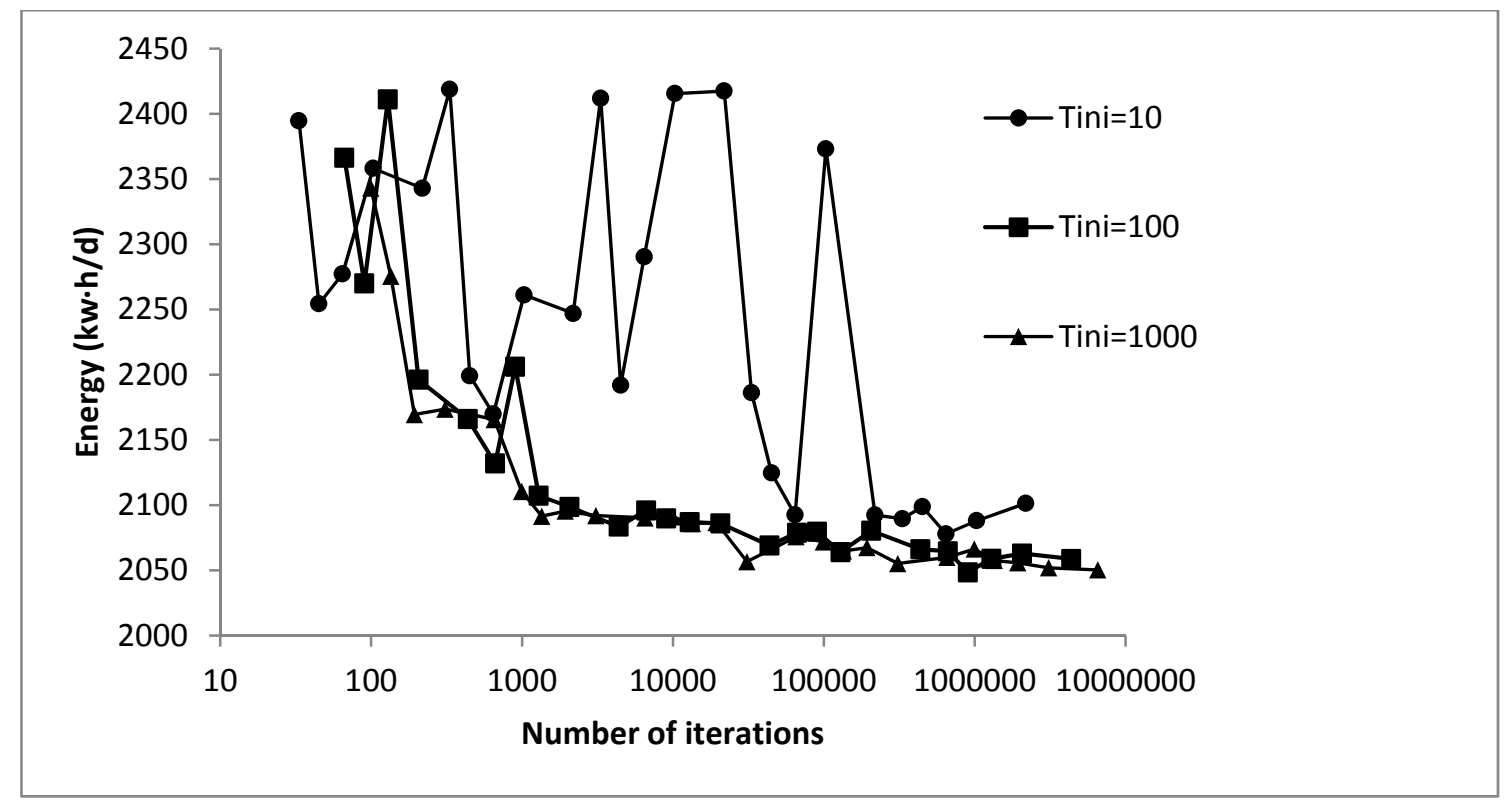




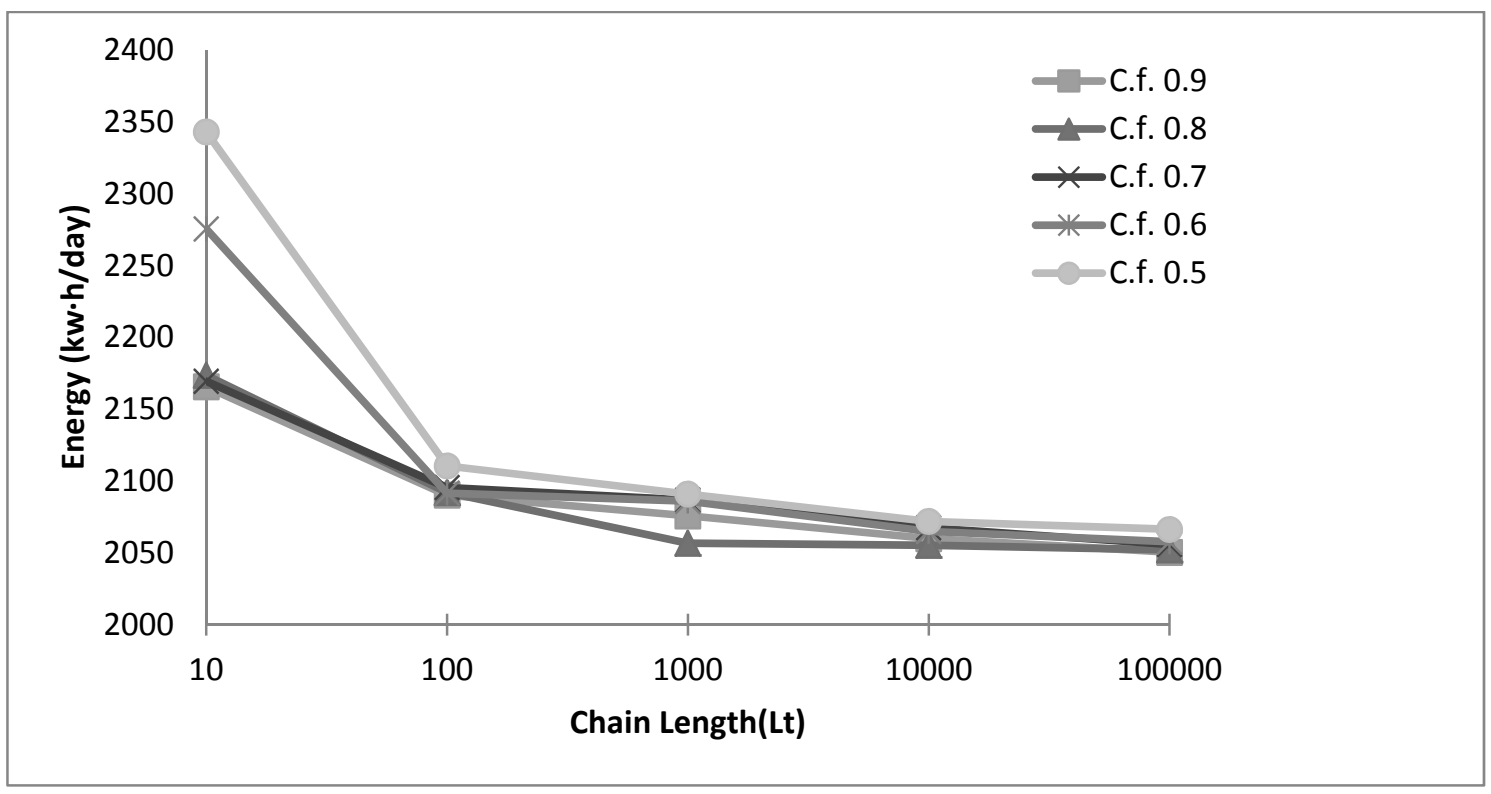




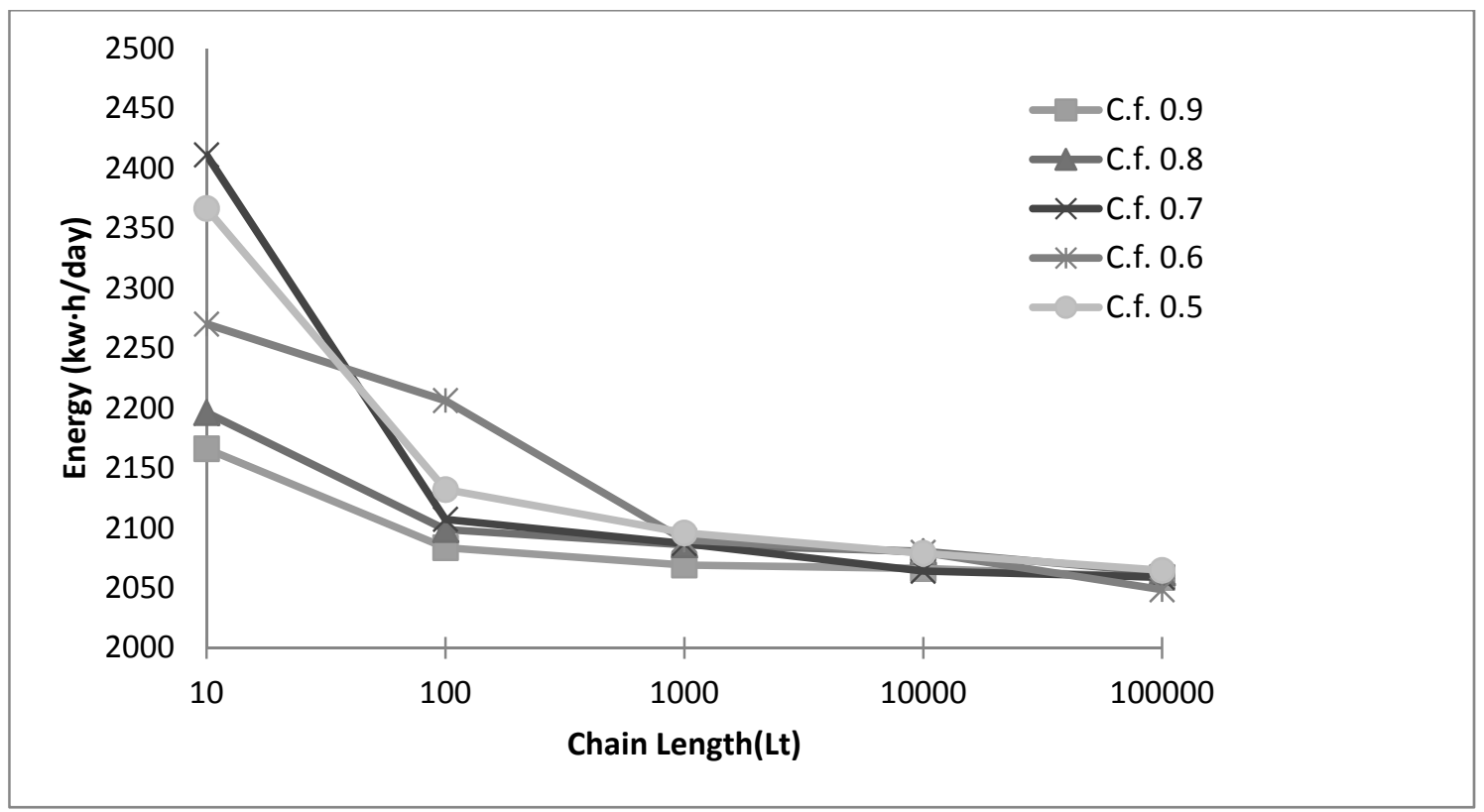




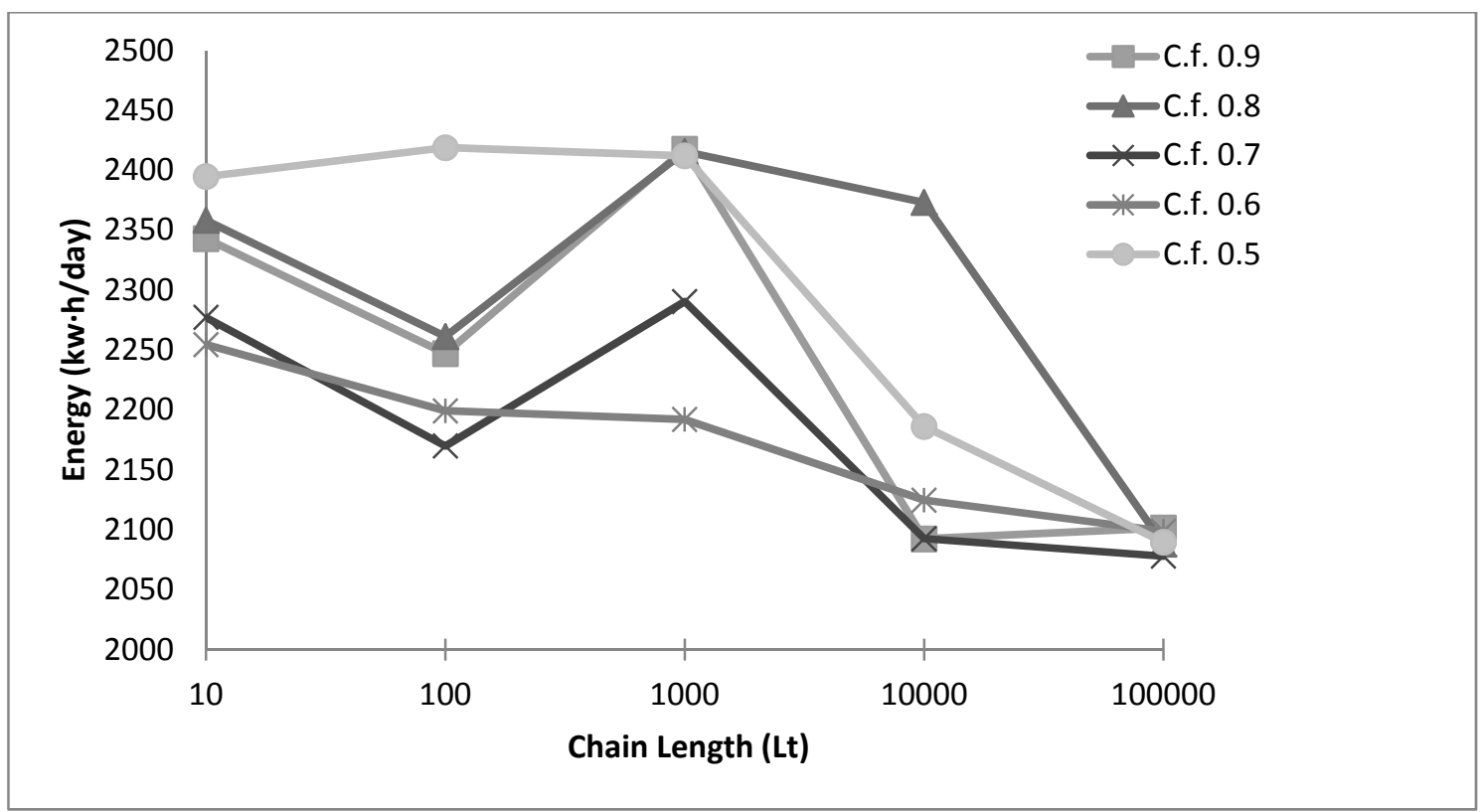


Table 1. Energy consumption in the sectorized network according to the elevation of hydrants.

\begin{tabular}{|c|c|c|c|c|c|c|c|c|c|c|c|c|}
\hline \multirow{2}{*}{$\begin{array}{l}\text { Operating } \\
\text { Sector }\end{array}$} & \multirow{2}{*}{$Q_{s}\left(L s^{-1}\right)$} & \multirow{2}{*}{$t_{r}(h)$} & \multirow{2}{*}{$H_{i}(m)$} & \multicolumn{4}{|c|}{ Variable-speed pump } & \multicolumn{3}{|c|}{ Fixed-speed pumps } & \multirow{2}{*}{$P_{a b s}(K w)$} & \multirow{2}{*}{$\begin{array}{c}\text { Energy } \\
\left(K w \cdot h d^{-1}\right.\end{array}$} \\
\hline & & & & $N_{v s}$ & $\alpha$ & $Q_{1}\left(L s^{-1}\right)$ & $\eta(\%)$ & $N_{f s}$ & $Q\left(L s^{-1}\right)$ & $\eta(\%)$ & & \\
\hline 1 & 120.0 & 3.3 & 73.6 & 1 & 0.85 & 42.4 & 73.1 & 1 & 77.7 & 67.3 & 125.2 & 412 \\
\hline 2 & 128.2 & 3.3 & 85.8 & 1 & 0.98 & 61.5 & 74.6 & 1 & 66.7 & 73.6 & 145.7 & 479 \\
\hline 3 & 127.3 & 3.3 & 83.8 & 1 & 0.96 & 58.7 & 74.8 & 1 & 68.6 & 72.9 & 142.0 & 467 \\
\hline 4 & 129.8 & 3.3 & 78.3 & 1 & 0.92 & 56.2 & 74.9 & 1 & 73.7 & 70.2 & 138.2 & 455 \\
\hline 5 & 147.5 & 3.3 & 85.8 & 1 & 0.85 & 14.1 & 36.2 & 2 & 66.7 & 73.6 & 185.4 & 610 \\
\hline \multicolumn{12}{|c|}{ TOTAL } & 2423 \\
\hline
\end{tabular}

Table 2. Simulated annealing solutions achieved.

\begin{tabular}{cccccccc}
\hline \multirow{2}{*}{$T_{o}$} & $L_{t}$ & $\begin{array}{c}\text { Initial solution } \\
\text { Energy }\left(\text { Kw } h d^{-1}\right)\end{array}$ & \multicolumn{5}{c}{ Simulated Annealing Solution. Energy $\left(\right.$ Kw $\left.\cdot h d^{-1}\right)$} \\
\hline 10 & 10 & 2423 & 2343 & 2358 & 2277 & 2254 & 2395 \\
10 & 100 & 2423 & 2247 & 2261 & 2170 & 2199 & 2419 \\
10 & 1000 & 2423 & 2417 & 2416 & 2290 & 2192 & 2412 \\
10 & 10000 & 2423 & 2092 & 2373 & 2093 & 2125 & 2186 \\
10 & 100000 & 2423 & 2101 & 2088 & 2078 & 2099 & 2090 \\
\hline 100 & 10 & 2423 & 2166 & 2196 & 2411 & 2270 & 2366 \\
100 & 100 & 2423 & 2084 & 2099 & 2107 & 2206 & 2132 \\
100 & 1000 & 2423 & 2069 & 2086 & 2087 & 2090 & 2096 \\
100 & 10000 & 2423 & 2066 & 2080 & 2064 & 2080 & 2079 \\
100 & 100000 & 2423 & 2059 & 2063 & 2059 & 2049 & 2065 \\
\hline 1000 & 10 & 2423 & 2166 & 2174 & 2170 & 2276 & 2343 \\
1000 & 100 & 2423 & 2090 & 2092 & 2095 & 2092 & 2111 \\
1000 & 1000 & 2423 & 2076 & 2057 & 2087 & 2086 & 2091 \\
1000 & 10000 & 2423 & 2060 & 2055 & 2068 & 2065 & 2072 \\
1000 & 100000 & 2423 & 2050 & 2052 & 2056 & 2058 & 2066 \\
\hline
\end{tabular}

Table 3. Energy consumption in the network under the scenario selected by SA.

\begin{tabular}{|c|c|c|c|c|c|c|c|c|c|c|c|c|}
\hline \multirow{2}{*}{$\begin{array}{l}\text { Operating } \\
\text { Sector }\end{array}$} & \multirow{2}{*}{$Q_{s}\left(L s^{-1}\right)$} & \multirow{2}{*}{$t_{r}(h)$} & \multirow{2}{*}{$H_{i}(m)$} & \multicolumn{4}{|c|}{ Variable-speed pump } & \multicolumn{3}{|c|}{ Fixed-speed pumps } & \multirow{2}{*}{$P_{a b s}(K w)$} & \multirow{2}{*}{$\begin{array}{c}\text { Energy } \\
\left(K w \cdot h d^{-1}\right)\end{array}$} \\
\hline & & & & $N_{v s}$ & $\alpha$ & $Q_{1}\left(L s^{-1}\right)$ & $\eta(\%)$ & $N_{f s}$ & $Q\left(L s^{-1}\right)$ & $\eta(\%)$ & & \\
\hline 1 & 142.2 & 3.3 & 59.6 & 1 & 0.82 & 53.6 & 74.1 & 1 & 88.6 & 55.8 & 135.0 & 444 \\
\hline 2 & 147.2 & 3.3 & 60.4 & 1 & 0.85 & 59.2 & 72.6 & 1 & 88.0 & 56.6 & 140.5 & 462 \\
\hline 3 & 150.7 & 3.3 & 61.7 & 1 & 0.88 & 63.6 & 71.0 & 1 & 87.0 & 57.8 & 145.4 & 478 \\
\hline 4 & 139.0 & 3.3 & 67.0 & 1 & 0.87 & 56.0 & 74.3 & 1 & 83.0 & 62.3 & 137.0 & 451 \\
\hline 5 & 73.9 & 3.3 & 57.3 & 1 & 0.91 & 73.9 & 64.1 & 0 & 90.2 & 53.7 & 64.8 & 213 \\
\hline \multicolumn{12}{|c|}{ TOTAL } & 2049 \\
\hline
\end{tabular}


Table 4. Detailed Energy consumption calculation on-demand functioning.

\begin{tabular}{|c|c|c|c|c|c|c|c|c|c|c|c|c|c|c|c|c|c|c|c|c|}
\hline \multirow{2}{*}{$\begin{array}{c}Q_{d} \\
\text { Interval }\end{array}$} & \multirow{2}{*}{$\begin{array}{l}Q_{d-\min } \\
\left(L \cdot s^{-1}\right)\end{array}$} & \multirow{2}{*}{$\begin{array}{l}Q_{d-\max } \\
\left(L \cdot s^{-1}\right)\end{array}$} & \multirow{2}{*}{$\begin{array}{c}Q_{d-\text {-average }} \\
\left(L \cdot s^{-1}\right)\end{array}$} & \multirow{2}{*}{$\begin{array}{l}\text { Frequency } \\
\qquad \mathrm{Q}^{(*)}\end{array}$} & \multirow{2}{*}{$\begin{array}{c}\text { Time } \\
\text { functioning } \\
\text { into } Q \\
\text { interval (h) }\end{array}$} & \multirow{2}{*}{$\begin{array}{c}\mathrm{H} \\
\text { Interval }\end{array}$} & \multirow{2}{*}{$\begin{array}{l}\text { Frequency } \\
\qquad \mathrm{H}^{(* *)}\end{array}$} & \multirow{2}{*}{$\begin{array}{l}\mathrm{H}_{\min } \\
(\mathrm{m})\end{array}$} & \multirow{2}{*}{$\begin{array}{l}\mathrm{H}_{\max } \\
(\mathrm{m})\end{array}$} & \multirow{2}{*}{$\begin{array}{c}\mathrm{H}_{\text {average }} \\
(\mathrm{m})\end{array}$} & \multirow{2}{*}{$\begin{array}{c}\text { Time } \\
\text { functioning } \\
\text { into } \mathrm{H} \\
\text { interval (h) }\end{array}$} & \multicolumn{4}{|c|}{ Variable-speed pump } & \multicolumn{3}{|c|}{ Fixed-speed pumps } & \multirow{2}{*}{$\begin{array}{l}P_{a b s} \\
(k w)\end{array}$} & \multirow{2}{*}{$\begin{array}{l}\text { Energy } \\
(\mathrm{Kw} \cdot \mathrm{h})\end{array}$} \\
\hline & & & & & & & & & & & & $N_{v s}$ & $\alpha$ & $Q\left(L s^{-1}\right)$ & $\eta(\%)$ & $N_{f s}$ & $Q\left(L s^{-1}\right)$ & $\eta(\%)$ & & \\
\hline \multirow[t]{11}{*}{ Q1 } & 3.2 & 30 & 16.6 & 0.0020 & 0.03 & $\mathrm{H} 1$ & 0.0553 & 47.8 & 50 & 48.92 & 0.002 & 1 & 0.65 & 16.6 & 50.8 & 0 & - & - & 15.7 & 0.03 \\
\hline & & & & & & $\mathrm{H} 2$ & 0.1859 & 50 & 55 & 52.5 & 0.01 & 1 & 0.67 & 16.6 & 49.6 & 0 & - & - & 17.2 & 0.1 \\
\hline & & & & & & H3 & 0.2613 & 55 & 60 & 57.5 & 0.01 & 1 & 0.70 & 16.6 & 48.0 & 0 & - & - & 19.5 & 0.2 \\
\hline & & & & & & $\mathrm{H} 4$ & 0.2161 & 60 & 65 & 62.5 & 0.01 & 1 & 0.73 & 16.6 & 46.6 & 0 & - & - & 21.9 & 0.2 \\
\hline & & & & & & H5 & 0.1960 & 65 & 70 & 67.5 & 0.01 & 1 & 0.76 & 16.6 & 45.3 & 0 & - & - & 24.3 & 0.2 \\
\hline & & & & & & $\mathrm{H} 6$ & 0.0603 & 70 & 75 & 72.5 & 0.00 & 1 & 0.79 & 16.6 & 44.1 & 0 & - & - & 26.8 & 0.05 \\
\hline & & & & & & $\mathrm{H} 7$ & 0.0251 & 75 & 80 & 77.5 & 0.00 & 1 & 0.81 & 16.6 & 43.0 & 0 & - & - & 29.4 & 0.02 \\
\hline & & & & & & $\mathrm{H} 8$ & 0.0000 & 80 & 85 & 82.5 & 0.00 & 1 & 0.84 & 16.6 & 41.9 & 0 & - & - & - & 0.0 \\
\hline & & & & & & $\mathrm{H} 9$ & 0.0000 & 85 & 90 & 87.5 & 0.00 & 1 & 0.86 & 16.6 & 41.0 & 0 & - & - & - & 0.0 \\
\hline & & & & & & $\mathrm{H} 10$ & 0.0000 & 90 & 99.2 & 94.6 & 0.00 & 1 & 0.90 & 16.6 & 39.7 & 0 & - & - & - & 0.0 \\
\hline & & & & & & & 1.0000 & & & & & & & & & & & & & 0.7 \\
\hline \multirow[t]{11}{*}{ Q2 } & 30 & 60 & 45 & 0.0276 & 0.45 & $\mathrm{H} 1$ & 0.0000 & 47.8 & 50 & 48.92 & 0.00 & 1 & 0.73 & 45.0 & 74.8 & 0 & - & - & - & 0.0 \\
\hline & & & & & & $\mathrm{H} 2$ & 0.0189 & 50 & 55 & 52.5 & 0.01 & 1 & 0.75 & 45.0 & 74.9 & 0 & - & - & 30.9 & 0.3 \\
\hline & & & & & & H3 & 0.1118 & 55 & 60 & 57.5 & 0.05 & 1 & 0.78 & 45.0 & 74.9 & 0 & - & - & 33.9 & 1.7 \\
\hline & & & & & & $\mathrm{H} 4$ & 0.2663 & 60 & 65 & 62.5 & 0.12 & 1 & 0.81 & 45.0 & 74.8 & 0 & - & - & 36.9 & 4.5 \\
\hline & & & & & & $\mathrm{H} 5$ & 0.3770 & 65 & 70 & 67.5 & 0.17 & 1 & 0.83 & 45.0 & 74.5 & 0 & - & - & 40.0 & 6.8 \\
\hline & & & & & & $\mathrm{H} 6$ & 0.1494 & 70 & 75 & 72.5 & 0.07 & 1 & 0.86 & 45.0 & 74.1 & 0 & - & - & 43.2 & 2.9 \\
\hline & & & & & & $\mathrm{H} 7$ & 0.0616 & 75 & 80 & 77.5 & 0.03 & 1 & 0.88 & 45.0 & 73.7 & 0 & - & - & 46.5 & 1.3 \\
\hline & & & & & & $\mathrm{H} 8$ & 0.0142 & 80 & 85 & 82.5 & 0.01 & 1 & 0.90 & 45.0 & 73.2 & 0 & - & - & 49.8 & 0.3 \\
\hline & & & & & & $\mathrm{H} 9$ & 0.0000 & 85 & 90 & 87.5 & 0.00 & 1 & 0.93 & 45.0 & 72.7 & 0 & - & - & - & 0.0 \\
\hline & & & & & & $\mathrm{H} 10$ & 0.0007 & 90 & 99.2 & 94.6 & 0.0003 & 1 & 0.96 & 45.0 & 71.9 & 0 & - & - & 58.1 & 0.02 \\
\hline & & & & & & & 1.0000 & & & & & & & & & & & & & 17.9 \\
\hline
\end{tabular}




\begin{tabular}{|c|c|c|c|c|c|c|c|c|c|c|c|c|c|c|c|c|c|c|c|c|}
\hline \multirow[t]{11}{*}{ Q3 } & 60 & 90 & 75 & 0.1269 & 2.09 & $\mathrm{H} 1$ & 0.0000 & 47.8 & 50 & 48.92 & 0.00 & 1 & 0.88 & 75.0 & 59.6 & 0 & - & - & - & 0.0 \\
\hline & & & & & & $\mathrm{H} 2$ & 0.0008 & 50 & 55 & 52.5 & 0.00 & 1 & 0.89 & 75.0 & 61.4 & 0 & - & - & 63.0 & 0.1 \\
\hline & & & & & & H3 & 0.0272 & 55 & 60 & 57.5 & 0.06 & 1 & 0.92 & 75.0 & 63.5 & 0 & - & - & 66.6 & 3.8 \\
\hline & & & & & & $\mathrm{H} 4$ & 0.1555 & 60 & 65 & 62.5 & 0.32 & 1 & 0.94 & 75.0 & 65.4 & 0 & - & - & 70.3 & 22.8 \\
\hline & & & & & & H5 & 0.4441 & 65 & 70 & 67.5 & 0.93 & 1 & 0.96 & 75.0 & 67.0 & 0 & - & - & 74.2 & 68.7 \\
\hline & & & & & & H6 & 0.2236 & 70 & 75 & 72.5 & 0.47 & 1 & 0.98 & 75.0 & 68.3 & 0 & - & - & 78.1 & 36.4 \\
\hline & & & & & & $\mathrm{H7}$ & 0.1093 & 75 & 80 & 77.5 & 0.23 & 1 & 0.80 & 0.7 & 2.0 & 1 & 74.4 & 69.8 & 105.2 & 24.0 \\
\hline & & & & & & $\mathrm{H} 8$ & 0.0359 & 80 & 85 & 82.5 & 0.08 & 1 & 0.83 & 5.1 & 14.9 & 1 & 69.9 & 72.3 & 106.0 & 8.0 \\
\hline & & & & & & $\mathrm{H} 9$ & 0.0035 & 85 & 90 & 87.5 & 0.01 & 1 & 0.86 & 9.9 & 26.6 & 1 & 65.1 & 74.1 & 107.4 & 0.8 \\
\hline & & & & & & $\mathrm{H} 10$ & 0.0002 & 90 & 99.2 & 94.6 & 0.0003 & 1 & 0.90 & 17.4 & 41.2 & 1 & 57.6 & 74.9 & 110.5 & 0.04 \\
\hline & & & & & & & 1.0000 & & & & & & & & & & & & & 164.7 \\
\hline \multirow[t]{11}{*}{ Q4 } & 90 & 120 & 105 & 0.2614 & 4.30 & $\mathrm{H} 1$ & 0.0000 & 47.8 & 50 & 48.92 & 0.00 & 1 & 0.64 & 9.0 & 31.3 & 1 & 96.1 & 45.0 & - & 0.0 \\
\hline & & & & & & $\mathrm{H} 2$ & 0.0000 & 50 & 55 & 52.5 & 0.00 & 1 & 0.67 & 11.4 & 37.2 & 1 & 93.6 & 48.8 & - & 0.0 \\
\hline & & & & & & H3 & 0.0046 & 55 & 60 & 57.5 & 0.02 & 1 & 0.70 & 14.9 & 44.3 & 1 & 90.1 & 53.9 & 113.3 & 2.3 \\
\hline & & & & & & $\mathrm{H} 4$ & 0.0659 & 60 & 65 & 62.5 & 0.28 & 1 & 0.74 & 18.6 & 50.5 & 1 & 86.4 & 58.5 & 113.1 & 32.0 \\
\hline & & & & & & H5 & 0.3860 & 65 & 70 & 67.5 & 1.66 & 1 & 0.77 & 22.4 & 55.8 & 1 & 82.6 & 62.8 & 113.8 & 188.9 \\
\hline & & & & & & H6 & 0.3208 & 70 & 75 & 72.5 & 1.38 & 1 & 0.80 & 26.4 & 60.3 & 1 & 78.6 & 66.5 & 115.2 & 158.9 \\
\hline & & & & & & $\mathrm{H} 7$ & 0.1437 & 75 & 80 & 77.5 & 0.62 & 1 & 0.84 & 30.7 & 64.1 & 1 & 74.4 & 69.8 & 117.4 & 72.5 \\
\hline & & & & & & $\mathrm{H} 8$ & 0.0678 & 80 & 85 & 82.5 & 0.29 & 1 & 0.87 & 35.1 & 67.4 & 1 & 69.9 & 72.3 & 120.4 & 35.1 \\
\hline & & & & & & H9 & 0.0106 & 85 & 90 & 87.5 & 0.05 & 1 & 0.91 & 39.9 & 70.1 & 1 & 65.1 & 74.1 & 124.3 & 5.7 \\
\hline & & & & & & $\mathrm{H} 10$ & 0.0007 & 90 & 99.2 & 94.6 & 0.003 & 1 & 0.96 & 47.4 & 72.9 & 1 & 57.6 & 74.9 & 131.7 & 0.4 \\
\hline & & & & & & & 1.0000 & & & & & & & & & & & & & 495.8 \\
\hline \multirow[t]{9}{*}{ Q5 } & 120 & 150 & 135 & 0.2900 & 4.77 & $\mathrm{H} 1$ & 0.0000 & 47.8 & 50 & 48.92 & 0.00 & 1 & 0.71 & 39.0 & 74.6 & 1 & 96.1 & 45.0 & - & 0.0 \\
\hline & & & & & & $\mathrm{H} 2$ & 0.0000 & 50 & 55 & 52.5 & 0.00 & 1 & 0.74 & 41.4 & 74.8 & 1 & 93.6 & 48.8 & - & 0.0 \\
\hline & & & & & & $\mathrm{H} 3$ & 0.0004 & 55 & 60 & 57.5 & 0.002 & 1 & 0.78 & 44.9 & 74.9 & 1 & 90.1 & 53.9 & 128.2 & 0.3 \\
\hline & & & & & & $\mathrm{H} 4$ & 0.0175 & 60 & 65 & 62.5 & 0.08 & 1 & 0.82 & 48.6 & 75.0 & 1 & 86.4 & 58.5 & 130.3 & 10.9 \\
\hline & & & & & & $\mathrm{H} 5$ & 0.2431 & 65 & 70 & 67.5 & 1.16 & 1 & 0.86 & 52.4 & 74.9 & 1 & 82.6 & 62.8 & 133.5 & 154.8 \\
\hline & & & & & & $\mathrm{H} 6$ & 0.4208 & 70 & 75 & 72.5 & 2.01 & 1 & 0.90 & 56.4 & 74.6 & 1 & 78.6 & 66.5 & 137.8 & 276.6 \\
\hline & & & & & & $\mathrm{H} 7$ & 0.1534 & 75 & 80 & 77.5 & 0.73 & 1 & 0.94 & 60.7 & 74.2 & 1 & 74.4 & 69.8 & 143.2 & 104.8 \\
\hline & & & & & & $\mathrm{H} 8$ & 0.1409 & 80 & 85 & 82.5 & 0.67 & 1 & 0.98 & 65.1 & 73.7 & 1 & 69.9 & 72.3 & 149.8 & 100.6 \\
\hline & & & & & & $\mathrm{H} 9$ & 0.0215 & 85 & 90 & 87.5 & 0.10 & 1 & 0.85 & 4.9 & 13.8 & 2 & 65.1 & 74.1 & 181.0 & 18.6 \\
\hline
\end{tabular}




\begin{tabular}{|c|c|c|c|c|c|c|c|c|c|c|c|c|c|c|c|c|c|c|c|c|}
\hline & & & & & & $\mathrm{H} 10$ & 0.0024 & 90 & 99.2 & 94.6 & 0.01 & 1 & 0.90 & 19.8 & 45.5 & 2 & 57.6 & 74.9 & 183.1 & 2.1 \\
\hline & & & & & & & 1.0000 & & & & & & & & & & & & & 668.7 \\
\hline \multirow[t]{11}{*}{ Q6 } & 150 & 180 & 165 & 0.1882 & 3.10 & $\mathrm{H} 1$ & 0.0000 & 47.8 & 50 & 48.92 & 0.00 & 1 & 0.84 & 69.0 & 63.7 & 1 & 96.1 & 45.0 & & 0.0 \\
\hline & & & & & & $\mathrm{H} 2$ & 0.0000 & 50 & 55 & 52.5 & 0.00 & 1 & 0.87 & 71.4 & 63.7 & 1 & 93.6 & 48.8 & - & 0.0 \\
\hline & & & & & & H3 & 0.0001 & 55 & 60 & 57.5 & 0.0002 & 1 & 0.92 & 74.9 & 63.6 & 1 & 90.1 & 53.9 & 160.8 & 0.03 \\
\hline & & & & & & $\mathrm{H} 4$ & 0.0040 & 60 & 65 & 62.5 & 0.01 & 1 & 0.96 & 78.6 & 63.3 & 1 & 86.4 & 58.5 & 166.7 & 2.1 \\
\hline & & & & & & H5 & 0.1117 & 65 & 70 & 67.5 & 0.35 & 1 & 1.00 & 82.4 & 62.9 & 1 & 82.6 & 62.8 & 174.0 & 60.1 \\
\hline & & & & & & $\mathrm{H} 6$ & 0.4398 & 70 & 75 & 72.5 & 1.36 & 1 & 0.78 & 7.8 & 23.4 & 2 & 78.6 & 66.5 & 191.8 & 261.1 \\
\hline & & & & & & $\mathrm{H} 7$ & 0.1529 & 75 & 80 & 77.5 & 0.47 & 1 & 0.81 & 16.3 & 42.3 & 2 & 74.4 & 69.8 & 191.4 & 90.6 \\
\hline & & & & & & $\mathrm{H} 8$ & 0.2447 & 80 & 85 & 82.5 & 0.76 & 1 & 0.85 & 25.3 & 56.5 & 2 & 69.9 & 72.3 & 192.6 & 145.9 \\
\hline & & & & & & H9 & 0.0422 & 85 & 90 & 87.5 & 0.13 & 1 & 0.90 & 34.9 & 66.3 & 2 & 65.1 & 74.1 & 195.9 & 25.6 \\
\hline & & & & & & $\mathrm{H} 10$ & 0.0046 & 90 & 99.2 & 94.6 & 0.01 & 1 & 0.97 & 49.8 & 73.7 & 2 & 57.6 & 74.9 & 205.4 & 2.9 \\
\hline & & & & & & & 1.0000 & & & & & & & & & & & & & 588.4 \\
\hline \multirow[t]{11}{*}{ Q7 } & 180 & 210 & 195 & 0.0776 & 1.28 & $\mathrm{H} 1$ & 0.0000 & 47.8 & 50 & 48.92 & 0.00 & 1 & 0.64 & 2.9 & 11.1 & 2 & 96.1 & 45.0 & - & 0.0 \\
\hline & & & & & & $\mathrm{H} 2$ & 0.0000 & 50 & 55 & 52.5 & 0.00 & 1 & 0.66 & 7.8 & 26.9 & 2 & 93.6 & 48.8 & - & 0.0 \\
\hline & & & & & & H3 & 0.0000 & 55 & 60 & 57.5 & 0.00 & 1 & 0.70 & 14.8 & 44.1 & 2 & 90.1 & 53.9 & - & 0.0 \\
\hline & & & & & & $\mathrm{H} 4$ & 0.0001 & 60 & 65 & 62.5 & 0.0002 & 1 & 0.74 & 22.2 & 56.7 & 2 & 86.4 & 58.5 & 205.1 & 0.03 \\
\hline & & & & & & H5 & 0.0298 & 65 & 70 & 67.5 & 0.04 & 1 & 0.79 & 29.8 & 65.4 & 2 & 82.6 & 62.8 & 204.5 & 7.8 \\
\hline & & & & & & H6 & 0.3708 & 70 & 75 & 72.5 & 0.47 & 1 & 0.83 & 37.8 & 71.0 & 2 & 78.6 & 66.5 & 205.9 & 97.5 \\
\hline & & & & & & $\mathrm{H7}$ & 0.1783 & 75 & 80 & 77.5 & 0.23 & 1 & 0.88 & 46.3 & 74.0 & 2 & 74.4 & 69.8 & 209.7 & 47.8 \\
\hline & & & & & & $\mathrm{H} 8$ & 0.3119 & 80 & 85 & 82.5 & 0.40 & 1 & 0.94 & 55.3 & 75.0 & 2 & 69.9 & 72.3 & 216.1 & 86.1 \\
\hline & & & & & & H9 & 0.0976 & 85 & 90 & 87.5 & 0.12 & 1 & 1.00 & 64.9 & 74.2 & 2 & 65.1 & 74.1 & 225.9 & 28.2 \\
\hline & & & & & & $\mathrm{H} 10$ & 0.0114 & 90 & 99.2 & 94.6 & 0.01 & 1 & 0.90 & 22.2 & 49.4 & 3 & 57.6 & 74.9 & 255.7 & 3.7 \\
\hline & & & & & & & 1.0000 & & & & & & & & & & & & & 271.1 \\
\hline \multirow[t]{6}{*}{ Q8 } & 210 & 240 & 225 & 0.0216 & 0.35 & $\mathrm{H} 1$ & 0.0000 & 47.8 & 50 & 48.92 & 0.00 & 1 & 0.69 & 32.9 & 72.2 & 2 & 96.1 & 45.0 & - & 0.0 \\
\hline & & & & & & $\mathrm{H} 2$ & 0.0000 & 50 & 55 & 52.5 & 0.00 & 1 & 0.73 & 37.8 & 73.9 & 2 & 93.6 & 48.8 & - & 0.0 \\
\hline & & & & & & $\mathrm{H} 3$ & 0.0000 & 55 & 60 & 57.5 & 0.00 & 1 & 0.78 & 44.8 & 74.9 & 2 & 90.1 & 53.9 & - & 0.0 \\
\hline & & & & & & $\mathrm{H} 4$ & 0.0000 & 60 & 65 & 62.5 & 0.00 & 1 & 0.83 & 52.2 & 74.7 & 2 & 86.4 & 58.5 & - & 0.0 \\
\hline & & & & & & $\mathrm{H} 5$ & 0.0037 & 65 & 70 & 67.5 & 0.001 & 1 & 0.89 & 59.8 & 73.4 & 2 & 82.6 & 62.8 & 228.3 & 0.3 \\
\hline & & & & & & $\mathrm{H} 6$ & 0.2488 & 70 & 75 & 72.5 & 0.09 & 1 & 0.95 & 67.8 & 71.5 & 2 & 78.6 & 66.5 & 235.6 & 20.8 \\
\hline
\end{tabular}




\begin{tabular}{|c|c|c|c|c|c|c|c|c|c|c|c|c|c|c|c|c|c|c|c|c|}
\hline & & & & & & H7 & 0.2146 & 75 & 80 & 77.5 & 0.08 & 1 & 0.80 & 1.9 & 6.0 & 3 & 74.4 & 69.8 & 267.6 & 20.4 \\
\hline & & & & & & $\mathrm{H} 8$ & 0.3501 & 80 & 85 & 82.5 & 0.12 & 1 & 0.84 & 15.4 & 39.5 & 3 & 69.9 & 72.3 & 266.1 & 33.1 \\
\hline & & & & & & H9 & 0.1660 & 85 & 90 & 87.5 & 0.06 & 1 & 0.89 & 29.8 & 61.2 & 3 & 65.1 & 74.1 & 268.0 & 15.8 \\
\hline & & & & & & $\mathrm{H} 10$ & 0.0167 & 90 & 99.2 & 94.6 & 0.01 & 1 & 0.98 & 52.2 & 74.3 & 3 & 57.6 & 74.9 & 279.3 & 1.7 \\
\hline & & & & & & & 1.0000 & & & & & & & & & & & & & 92.0 \\
\hline \multirow[t]{11}{*}{ Q9 } & 240 & 270 & 255 & 0.0043 & 0.07 & $\mathrm{H} 1$ & 0.0000 & 47.8 & 50 & 48.92 & 0.00 & 1 & 0.81 & 62.9 & 67.6 & 2 & 96.1 & 45.0 & - & 0.0 \\
\hline & & & & & & $\mathrm{H} 2$ & 0.0000 & 50 & 55 & 52.5 & 0.00 & 1 & 0.86 & 67.8 & 66.0 & 2 & 93.6 & 48.8 & - & 0.0 \\
\hline & & & & & & H3 & 0.0000 & 55 & 60 & 57.5 & 0.00 & 1 & 0.92 & 74.8 & 63.7 & 2 & 90.1 & 53.9 & - & 0.0 \\
\hline & & & & & & $\mathrm{H} 4$ & 0.0000 & 60 & 65 & 62.5 & 0.00 & 1 & 0.98 & 82.2 & 61.2 & 2 & 86.4 & 58.5 & - & 0.0 \\
\hline & & & & & & H5 & 0.0000 & 65 & 70 & 67.5 & 0.00 & 1 & 0.75 & 7.2 & 22.4 & 3 & 82.6 & 62.8 & - & 0.0 \\
\hline & & & & & & $\mathrm{H} 6$ & 0.0962 & 70 & 75 & 72.5 & 0.01 & 1 & 0.79 & 19.3 & 49.1 & 3 & 78.6 & 66.5 & 279.9 & 1.9 \\
\hline & & & & & & $\mathrm{H} 7$ & 0.2512 & 75 & 80 & 77.5 & 0.02 & 1 & 0.84 & 31.9 & 65.5 & 3 & 74.4 & 69.8 & 280.3 & 4.9 \\
\hline & & & & & & $\mathrm{H} 8$ & 0.3732 & 80 & 85 & 82.5 & 0.03 & 1 & 0.90 & 45.4 & 73.3 & 3 & 69.9 & 72.3 & 284.7 & 7.5 \\
\hline & & & & & & H9 & 0.2512 & 85 & 90 & 87.5 & 0.02 & 1 & 0.98 & 59.8 & 74.9 & 3 & 65.1 & 74.1 & 294.7 & 5.2 \\
\hline & & & & & & $\mathrm{H} 10$ & 0.0282 & 90 & 99.2 & 94.6 & 0.002 & 1 & 0.91 & 24.6 & 53.0 & 4 & 57.6 & 74.9 & 328.4 & 0.7 \\
\hline & & & & & & & 1.0000 & & & & & & & & & & & & & 20.1 \\
\hline \multirow[t]{12}{*}{ Q10 } & 270 & 309 & 289.5 & 0.0005 & 0.01 & $\mathrm{H} 1$ & 0.0000 & 47.8 & 50 & 48.92 & 0.00 & 1 & 0.64 & 1.3 & 5.3 & 3 & 96.1 & 45.0 & - & 0.0 \\
\hline & & & & & & $\mathrm{H} 2$ & 0.0000 & 50 & 55 & 52.5 & 0.00 & 1 & 0.66 & 8.7 & 29.5 & 3 & 93.6 & 48.8 & - & 0.0 \\
\hline & & & & & & H3 & 0.0000 & 55 & 60 & 57.5 & 0.00 & 1 & 0.71 & 19.2 & 53.2 & 3 & 90.1 & 53.9 & - & 0.0 \\
\hline & & & & & & $\mathrm{H} 4$ & 0.0000 & 60 & 65 & 62.5 & 0.00 & 1 & 0.76 & 30.2 & 67.0 & 3 & 86.4 & 58.5 & - & 0.0 \\
\hline & & & & & & $\mathrm{H} 5$ & 0.0000 & 65 & 70 & 67.5 & 0.00 & 1 & 0.82 & 41.7 & 73.6 & 3 & 82.6 & 62.8 & - & 0.0 \\
\hline & & & & & & $\mathrm{H} 6$ & 0.1042 & 70 & 75 & 72.5 & 0.001 & 1 & 0.89 & 53.8 & 74.9 & 3 & 78.6 & 66.5 & 303.1 & 0.2 \\
\hline & & & & & & $\mathrm{H} 7$ & 0.1875 & 75 & 80 & 77.5 & 0.001 & 1 & 0.96 & 66.4 & 72.8 & 3 & 74.4 & 69.8 & 312.6 & 0.5 \\
\hline & & & & & & $\mathrm{H} 8$ & 0.2708 & 80 & 85 & 82.5 & 0.002 & 1 & 0.83 & 10.0 & 27.5 & 4 & 69.9 & 72.3 & 342.3 & 0.7 \\
\hline & & & & & & H9 & 0.3958 & 85 & 90 & 87.5 & 0.003 & 1 & 0.88 & 29.2 & 60.5 & 4 & 65.1 & 74.1 & 343.0 & 1.1 \\
\hline & & & & & & $\mathrm{H} 10$ & 0.0417 & 90 & 99.2 & 94.6 & 0.0003 & 1 & 0.89 & 1.4 & 4.1 & 5 & 57.6 & 74.9 & 389.6 & 0.1 \\
\hline & & & & & & & 1.0000 & & & & & & & & & & & & & 2.6 \\
\hline & & & & & & TOTAL & & & & & $16.45 \mathrm{~h}$ & & & & & & & & & 2321 \\
\hline
\end{tabular}

$(*)$ : Frequency into $\mathrm{Q}$ interval $=$ number of cases with $\mathrm{Q} \leq \mathrm{Qd}$-max divided total number of cases.

(**). Frequency into $\mathrm{H}$ interval $=$ number of cases into studied $\mathrm{Q}$ interval with $\mathrm{H} \leq \mathrm{H}_{\text {max }}$ divided total number of cases into studied $\mathrm{Q}$ interval. 
Table 5. Percentage of operating time related with the number of pumps needed

\begin{tabular}{ccc}
\hline No of pumps needed & Time $\left(\mathrm{hd}^{-1}\right)$ & \% of OT (\%) \\
\hline 1 & 2.3 & 13.8 \\
2 & 9.6 & 58.5 \\
3 & 4.2 & 25.5 \\
$>4$ & 0.4 & 2.2 \\
\hline TOTAL & 16.5 & 100
\end{tabular}

